\title{
Influence of Mesostriatal Afferents on the Development and Transmitter Regulation of Intrastriatal Grafts Derived from Embryonic Striatal Primordia
}

\author{
Fu-Chin Liu, ${ }^{1}$ Stephen B. Dunnett, ${ }^{2}$ and Ann M. Graybiel ${ }^{1}$ \\ 'Department of Brain and Cognitive Sciences, Massachusetts Institute of Technology, Cambridge, Massachusetts 02139, \\ and ${ }^{2}$ Department of Experimental Psychology, University of Cambridge, Cambridge CB2 3EB, United Kingdom
}

\begin{abstract}
Embryonic striatal grafts develop a modular organization in which patches of tissue enriched in many transmitter substances characteristic of striatum ( $P$ regions) are embedded in surrounds (NP regions) expressing only low levels of these substances. Catecholaminergic fibers from the host brain, identified by their expression of tyrosine hydroxylase (TH), grow into such grafts and selectively terminate in the striatum-like $P$ regions. This terminal pattern suggests that cellcell affinities between neurons of the substantia nigra and striatum may play a role either in the aggregation of the striatal cells into $P$ regions, or in the targeting of the THpositive fibers to the cell clusters. In the present study, we tested the first of these possibilities. Striatal grafts derived from embryonic day 15 striatal primordia were implanted into the ibotenate-damaged host striatum of rats previously treated with 6-hydroxydopamine (6-OHDA) to destroy TH-containing dopaminergic nigrostriatal afferents.
\end{abstract}

The 6-OHDA lesions that eliminated nearly all TH-like immunostaining in the host striatum also resulted in disappearance of nearly all TH-positive fibers in the grafts. In this dopamine-depleted environment, the grafts nevertheless developed a clear modular organization. They contained striatum-like patches with neurons expressing many of the neurochemicals characteristic of striatum (ACh, ChAT, calbindin- $D_{28 \mathrm{kO}}$, met-enkephalin, and dopamine- and adenosine 3':5'-monophosphate-regulated phosphoprotein-32,000 or DARPP-32), and these patches were surrounded by graft tissue expressing few of these striatal markers. These observations suggest that the ingrowth of TH-positive fibers from the host is not obligatory for the sorting out of striatal from nonstriatal cells during the formation of $P$ regions in embryonic striatal grafts.

Despite the fact that dopaminergic denervation of the host striatum did not disrupt either the aggregation of grafted cells into $P$ regions or the acquisition of striatal neurochem-

\footnotetext{
Received Mar. 4, 1992; revised May 29, 1992; accepted June 2, 1992.

This work was supported by NSF BNS-8720475, NATO Grant RG.85/0180 for International Collaboration in Research, and the Seaver Institute. We are grateful to Drs. R. W. Baughman, R. P. Elde, P. C. Emson, E. L. Gustafson, and $P$. Greengard for their generous gifts of antisera. We thank D. Major for help with the immunocytochemistry, G. Holm for help with the immunocytochemistry and the quantitative analysis, and H. F. Hall for help with the photography. F.C.L. was supported by the Markey Foundation and by the Cerebral Palsy Research Fund.

Correspondence should be addressed to Fu-Chin Liu, Ph.D., Massachusetts Institute of Technology, Department of Rrain and Cognitive Sciences, E25-618, 45 Carleton Street, Cambridge, MA 02139.

Copyright (C) 1992 Society for Neuroscience $0270-6474 / 92 / 124281-17 \$ 05.00 / 0$
}

ical phenotypes by cells in the $P$ regions, there were clear differences between the staining patterns of these grafts and grafts placed into dopamine-innervated striatum. Most striking was a sharp increase of met-enkephalin-like immunostaining in the $P$ zones of the denervated grafts. Upregulation of met-enkephalin is known to occur in the dopaminedepleted mature striatum, and was observed in the parts of host striatum surrounding the grafts on the side ipsilateral to the 6-OHDA lesions. This result suggests that functional interactions between dopaminergic and enkephalinergic systems can occur in the striatal circuits reconstructed by embryonic striatal grafting. More generally, our results suggest that TH-containing afferents from the host striatum, though not required for induction and maintenance of striatal phenotypy in striatal grafts, can chronically regulate neurotransmitter/neuromodulator expression in neurons of the striatum-like $P$ zones in a manner similar to that found for the normal striatum.

The dopamine-containing nigrostriatal tract probably is the first afferent system to innervate the developing striatum. The fibers of this tract start to innervate the striatal anlage as early as embryonic day 14 (E14) in the rat (Specht et al., 1981; Moon Edley and Herkenham, 1984; Voorn et al., 1988). At this time, only a small number of striatal cells have been born (Fentress et al., 1981; Bayer, 1984; Marchand and Lajoie, 1986), but dopamine D2-like receptor binding sites and D1 and D2 receptor mRNAs are present in the striatal primordium (Sales et al., 1989; Guennoun and Bloch, 1991; Schambra et al., 1991). Besides reaching the striatal anlage, a few of the early arriving dopamine-containing fibers also invade the ganglionic eminence (Specht et al., 1981; Newman-Gage and Graybiel, 1988; Voorn et al., 1988), which is the presumptive striatal primordium (Smart and Sturrock, 1979; Sidman and Rakic, 1982; Müller and O'Rahilly, 1988, 1990). Dopamine D2-like receptor binding sites and D1 and D2 receptor $m$ RNAs are also transiently expressed in the ventricular and subventricular zones of striatal primordium during early prenatal development (Sales et al., 1989; Guennoun and Bloch, 1991; Schambra el al., 1991).

Such early innervation of the ganglionic eminence and the striatal anlage by tyrosine hydroxylose $(\mathrm{TH})$-containing dopaminergic fibers raises the possibility that these dopaminergic fibers may regulate the development of striatal cells. For example, Laijiness et al. (1991) have shown that activation of dopamine D2 receptors in transfected Chinese hamster ovary cells results in an increase of mitogenesis. Thus, the transient dopamine-containing fibers in the ventricular zone may partic- 
ipate in the regulation of cell proliferation there. The earlyarriving dopamine-containing fibers in the striatal anlage, in which neurogenesis does not occur, may regulate neurite outgrowth (e.g., Lankford et al., 1988; McCobb et al., 1988), or they may support the survival of developing striatal neurons or be involved in the induction and/or maintenance of expression of neurochemical substances in these neurons. It has been shown in both the visual and somatosensory systems that denervation of target neurons during development can result in anterograde atrophic effects on target neurons (for review, see Purves and Lichtman, 1985; Oppenheim, 1991).

In the striatum, dopamine-containing nigrostriatal afferents exert control over striatal neuropeptides and also GABA through its synthetic enzyme glutamic acid decarboxylase (GAD) (Gale et al., 1988; Vernier et al., 1988; Besson et al., 1991; Soghomonian et al., 1991). Depletion of dopaminergic inputs to the mature striatum results in up- or downregulation of neuropeptides and neuropeptide mRNAs (Hong et al., 1978, 1985; Young et al., 1986; Li et al., 1987; Normand et al., 1987, 1988; Sivam et al., 1987; Voorn et al., 1987; Merchant et al., 1988; Walaas et al., 1989; Weiss and Chesselet, 1989; Jiang et al., 1990; Gerfen et al., 1991; for review, see Graybiel, 1990). For striatal tissue in culture, coculturing with ventral mesencephalon has been shown to increase the activity of ChAT and levels of substance $P$ (Kessler, 1986). However, it is not known how dopaminecontaining afferents affect striatal target neurons during development in vivo.

One strategy to approach this intriguing question is to destroy dopamine-containing afferents to the developing striatum using the catecholamine neurotoxin 6-hydroxydopamine (6-OHDA). Snyder-Keller (1991) has shown that nigrostriatal interactions can be studied as early as E17 in the rat by intraventricular injection of 6-OHDA into rat embryos, but injections earlier than E1 7 result in morbidity of the majority of embryos. In the study reported here, we reasoned that experiments with embryonic striatal grafts might allow these technical limitations to be circumvented, and might thus provide a system in which to study nigrostriatal interactions. We and others have previously shown that TH-containing nigrostriatal fibers of adult host brain are capable of innervating such embryonic striatal grafts, which can grow to a large size when placed in previously excitotoxindamaged host striatum (Pritzel et al., 1986; Graybiel et al., 1987; Isacson et al., 1987; Clarke et al., 1988; Wictorin et al., 1988, 1989; Liu et al., 1990; Labandeira-Garcia et al., 1991). In the grafts, the TH-positive fibers from the host form patches that are spatially aligned with AChE-rich patches seen in sections through the grafts (Graybiel et al., 1987; Wictorin et al., 1989; Liu et al., 1990). Many striatal markers are concentrated in the AChE-rich patch regions ( $P$ regions) of the grafts, whereas they are represented at low levels, if at all, in the nonpatch regions (NP regions) surrounding the AChE-rich $\mathrm{P}$ regions (Graybiel et al., 1989; Wictorin et al., 1989; Liu et al., 1990, 1991b). Thus, the $P$ regions probably represent aggregations of striatal tissue, whereas the AChE-poor NP zones may represent nonstriatal and/or immature striatal tissue (Graybiel et al., 1989; Wictorin et al., 1989; Liu et al., 1990, 1991b).

This situation suggests that affinities between nigral fibers and striatal cells could guide the formation of the patches of striatum-like tissues in the grafts. Local TH-containing fibers at the site of grafting could trigger the aggregation of cells into $P$ zones, and could influence expression of striatal phenotypy. Alterna- tively, intrinsic factors such as common cell-surface ligands and receptors (Lander, 1989) could lead to aggregation of committed striatal cells, which in turn could attract the host's nigrostriatal fibers (Graybiel and Hickey, 1982; Krushel et al., 1989).

In the study presented here and briefly summarized elsewhere (Liu et al., 1991a), we tested the first of these possibilities by transplanting E15 embryonic striatal primordia into the striatum of adult host rats in which nigrostriatal inputs had been previously removed by 6-OHDA lesions. We used the ibotenate-damaged striatum as the host system for the grafts, because in such excitotoxin-damaged striatum, embryonic striatal grafts grow to a large size, yet have patterns of expression of neurochemical markers similar to those observed in grafts placed into intact striatum (Zhou and Buchwald, 1989; Liu et al., 1990; Labandeira-Garcia et al., 1991; Lu et al., 1991; F.-C. Liu, S. B. Dunnett, and A. M. Graybiel, unpublished observations). We first determined with certainty that the TH-positive fibers in striatal grafts are derived from mesostriatal afferents of the host brain. We then tested whether the ingrowing TH-positive fibers are necessary for inducing or maintaining subpopulations of grafted E15 cells to form $P$ regions, and whether the absence of TH-containing fibers affected the development and maintenance of the neurochemical phenotypes of the grafted neurons.

\section{Materials and Methods}

Animals. Twenty-five female Sprague-Dawley rats (Harlan-OLAC, Bicester, Oxfordshire, UK), aged 10-14 weeks at the start of the study, were used as the host animals. Graft tissue was derived from embryos obtained by cesarian section from pregnant rats of the same outbred strain.

Denervation of dopaminergic afferents of the host striatum. Unilateral dopaminergic denervation of the right striatum of hosts $(n-19)$ was accomplished 29-32 d before grafting by injecting $4 \mu$ of $6-\mathrm{OHDA} \mathrm{HBr}$ $(2 \mu \mathrm{g} / \mu \mathrm{l}$, calculated as free base, dissolved in $0.1 \mathrm{mg}$ of ascorbic acid/ $\mathrm{ml}$ in saline) over $4 \mathrm{~min}$ at the following nigral coordinates: $\mathrm{A}=-4.4$ $\mathrm{mm}$ from bregma, $\mathrm{L}=-0.9 \mathrm{~mm}$ from midline, and $\mathrm{V}=7.8 \mathrm{~mm}$ from the dura mater with the nose bar set at $-2.3 \mathrm{~mm}$ below the interaural line. The rats were tested for methamphetamine $(2.5 \mathrm{mg} / \mathrm{kg})$-induced rotation in rotometer bowls $12 \mathrm{~d}$ after the 6-OHDA lesions to select rats with large lesions. The rats responding with over 300 turns in the $90 \mathrm{~min}$ test period were considered to have effective 6-OHDA lesions, and only these were chosen for grafting $(n=11)$.

Ibotenic acid lesions of the host striatum. Four weeks after the 6-OHDA lesions were made, the 11 rats with effective 6-OHDA lesions and 6 normal rats were given unilateral intrastriatal injections of $0.5 \mu \mathrm{l}$ of 0.06 $\mathrm{M}$ ibotenic acid dissolved in $0.1 \mathrm{M}$ phosphate buffer $(\mathrm{PB} ; \mathrm{pH} 7.4)$ over $3 \mathrm{~min}$ at each of two sites: $A=0.0 \mathrm{~mm}, \mathrm{~L}=-3.0 \mathrm{~mm}, \mathrm{~V}=5.0 \mathrm{~mm}$ and $\mathrm{A}=1.2 \mathrm{~mm}, \mathrm{~L}=-2.6 \mathrm{~mm}, \mathrm{~V}=5.0 \mathrm{~mm}$.

Embryonic striatal transplantation. One week after the ibotenic acid lesions, donor tissue was dissected from the lateral ganglionic eminence of embryonic day 15 embryos (crown rump length $=13-15 \mathrm{~mm}$ ), and cell suspensions were prepared for grafting as described elsewhere (Graybiel et al., 1989; Liu et al., 1990). Four microliters of the cell suspensions (36 striatal primordia/90 $\mu \mathrm{l}$ glucose-saline) were injected over $8 \mathrm{~min}$ into the degenerated striatum at coordinates located in the middle of the ibotenate-exposed tissue $(\mathrm{A}=0.8 \mathrm{~mm}, \mathrm{~L}=-2.8 \mathrm{~mm}$, and $\mathrm{V}=4.5$ $\mathrm{mm}$ ). After injection, the needle was left in place for $6 \mathrm{~min}$ before being slowly retracted. In this article, we employ the term denervated grafts to refer to striatal grafts implanted into host striatum denervated of catecholaminergic afferents by 6-OHDA lesions made prior to grafting. We refer to striatal grafts implanted into host striatum with intact catecholaminergic innervation as control grafts.

All the procedures involved in animal experiments reported here were approved by the Committee on Animal Care of the Massachusetts Institute of Technology.

Immunocytochemistry and histochemistry. Four to six months after transplantation, the grafted rats were deeply anesthetized and perfused through the heart with $4 \%$ paraformaldehyde in 0.1 M PB containing 

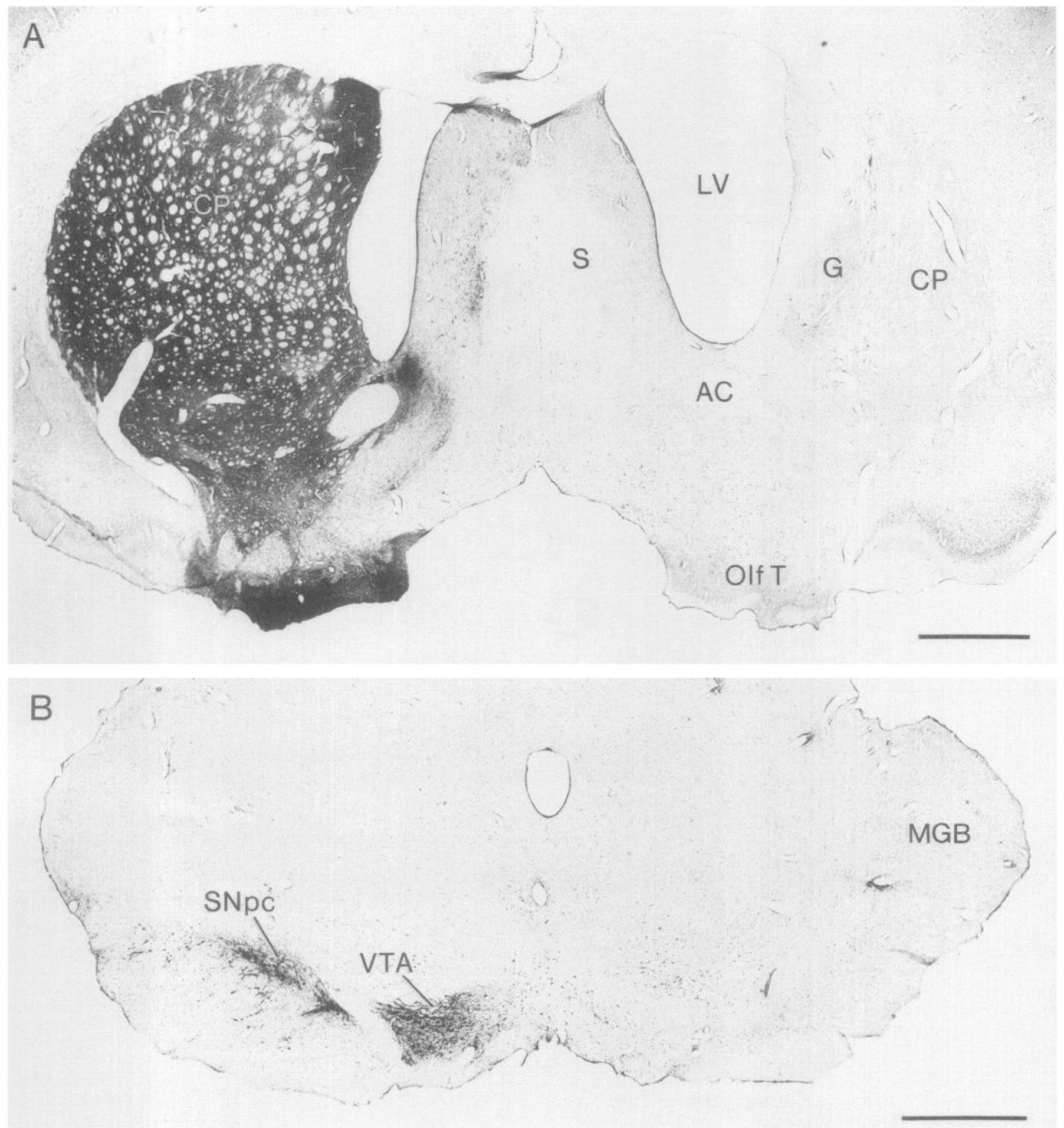

Figure 1. Photomicrographs illustrating the extent of the 6-OHDA lesion as demonstrated by TH-like immunostaining in the striatum $(A)$ and in the midbrain $(B)$ of case V18. $A$, Very little TH-like immunostaining is present in the striatal graft $(G)$ or in the surrounding host caudoputamen. However, one TH-positive neuron is present in the graft, but it is not visible at this magnification. Note that TH-like immunostaining in the nucleus accumbens and olfactory tubercle ipsilateral to the graft is also nearly eliminated by the lesion. $B$, No TH-positive neurons are present in the substantia nigra pars compacta or in the ventral tegmental area on the side ipsilateral to the lesion. $A C$, anterior commissure; $C P$, caudoputamen; $L V$, lateral ventricle; $M G B$, medial geniculate body; Olf $T$, olfactory tubercle; $S$, septum; $S N p c$, substantia nigra pars compacta; $V T A$, ventral tegmental area. Scale bars, $1 \mathrm{~mm}$. 

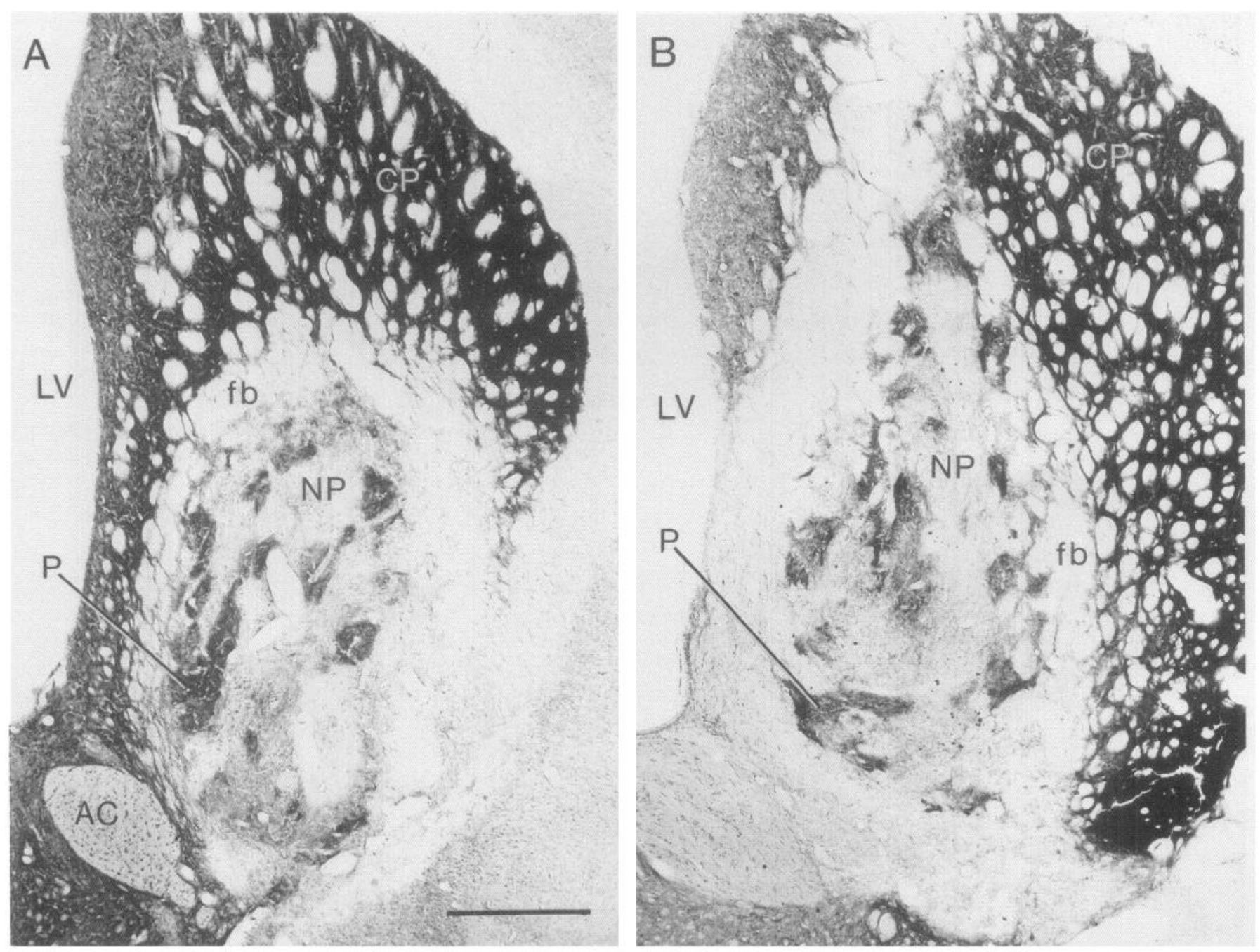

Figure 2. Photomicrographs of sections stained for AChE. $A$ shows a control striatal graft implanted into the caudoputamen $(C P)$ in case AG94, which lacks a 6-OHDA lesion. $B$ illustrates the striatal graft implanted into the denervated caudoputamen (case V-20). In both grafts, patches with enhanced AChE activity $(P)$ are embedded in AChE-poor surrounds $(N P)$. In some $\mathrm{P}$ regions of the denervated graft, the AChE activity is perceptibly lower than that in the $\mathrm{P}$ regions of the control graft. $A C$, anterior commissure; $L V$, lateral ventricle; $f b$, fiber bundles. Scale bar, $500 \mu \mathrm{m}$.

either $5 \%$ sucrose and $0.9 \%$ saline or $15 \%$ saturated picric acid ( $\mathrm{pH} 7.4)$. The brains were removed and kept in fresh fixative at $4^{\circ} \mathrm{C}$ for $2-4 \mathrm{hr}$, and then were stored in $20 \%$ sucrose in $0.1 \mathrm{M}$ phosphate-buffered saline. Brain tissue was sectioned in the coronal plane at $30 \mu \mathrm{m}$ on a freezing microtome. Immunostaining was performed with peroxidase-antiperoxidase immunocytochemistry as described previously (Sternberger, 1979; Graybiel, 1984; Graybiel and Chesselet, 1984; Liu et al., 1990). The concentrations of primary antisera were as follows: 1:240 for rabbit polyclonal anti-tyrosine hydroxylase antiserum (Eugene Tech, Allendale, $\mathrm{NJ}) ; 1: 1000$ for rabbit polyclonal anti-calbindin- $\mathrm{D}_{28 \mathrm{~K}}$ antiserum (gift from Dr. P. C. Emson, Institute of Animal Physiology, Babraham, Cambridge, UK); 1:1000 for rabbit polyclonal anti-met-enkephalin (gift from Dr. R. P. Elde, University of Minnesota, Minneapolis, MN); 1:20,000 for mouse monoclonal anti-dopamine- and adenosine $3^{\prime}: 5^{\prime}$ monophosphate-regulated phosphoprotein-32,000 (DARPP-32; gift from Drs. E. L. Gustafson and P. Greengard, The Rockefeller University, New York, NY); and 1:2000-2500 for mouse polyclonal anti-ChAT (gift from Dr. R. W. Baughman, Harvard Medical School, Boston, MA). A double-bridge procedure was followed routinely. For immunostaining controls, selected sections were incubated without the primary antisera. No staining was found in the controls. Acetylcholinesterase histochemistry was carried out according to a modified Geneser-Jensen and Blackstad method (Geneser-Jensen and Blackstad, 1971; Graybiel and Ragsdale, 1978).

Quantitative analysis. Densitometric measurements of met-enkephalin-like immunoreactivity were made with the aid of an image analysis system (Biocom, Les Ulis, France). Sections were chosen for the analysis from the brains of rats that had received 6-OHDA lesions before grafting ( $n=6,35$ sections) and from the brains of rats in which no 6-OHDA lesions were made ( $n=5,28$ sections). Measurements were made both on the side of the graft and on the contralateral side. The computer calculated the gray level of each pixel in a $512 \times 480$ matrix over a range of gray values from 0 (black, no light transmission) to 255 (white, maximum light transmission). For each section on the side contralateral to the grafts, the average gray levels within a square of $60 \mu \mathrm{m}^{2}$ were measured, respectively, for tissue in the medial caudoputamen adjacent to the lateral ventricle, in the center of the dorsal caudoputamen, in the lateral caudoputamen, and in two of the strong met-enkephalin-positive patches chosen randomly among those in the medial and ventral caudoputamen. All sets for measurements were carefully chosen to avoid large bundles of internal capsule fibers. On the side ipsilateral to the grafts, measurements with the same sample size were taken from matched regions of the host caudoputamen except that no measurements were obtained from the center of the caudoputamen into which most of the grafts were implanted. Measurements with $60 \mu \mathrm{m}^{2}$ squares were also taken from all of the $\mathrm{P}$ zones of the grafts and from three regions chosen randomly in the NP zones of the grafts. In a few sections, measurements could not be taken for the host striatum ipsilateral to the grafts due to the near-total depletion of host tissue by large ibotenate lesions.

In order to pool data from different sections from individual brains, we corrected for variations in staining from section to section. First, for each brain the gray values of the medial, the dorsocentral, and the lateral 
caudoputamen, and also the enkephalin-rich patches in the ventromedial caudoputamen contralateral to the graft side, were measured. These values were divided, respectively, by the average gray values measured for the lateral cortex and the lateral septum on the contralateral side in the same sections. The control cortical and septal measurements were made in three $60 \mu \mathrm{m}^{2}$ square samples centered, respectively, in the middle layers of the lateral cortex adjacent to the caudoputamen and in the lateral septal nucleus. The results of this analysis demonstrated that the immunostaining density in the contralateral caudoputament was not different in the 6-OHDA-treated animals and the normal animals except in the ventromedial patches (see Results). Therefore, the average immunostaining intensity of these unchanged contralateral striatal regions was used as the baseline for estimating changes on the side ipsilateral to the grafts. Gray values were then read for the grafts and adjoining host caudoputamen, and normalized values were obtained by dividing the gray values of the sampled regions on the ipsilateral side by the average gray values of the unchanged contralateral striatal regions. The resulting ratios were inverted before being plotted, because the gray level valucs measured by the computer program were inversely related to the staining intensity (minimum values $=$ dark staining; see above).

\section{Results}

Extent of 6-OHDA lesions as assessed with $T H$ immunohistochemistry

The 6-OHDA injection sites were centered in the medial forebrain bundle at the level of the posterior hypothalamus, and the lesions resulted in the disappearance of nearly all the $\mathrm{TH}$ positive neurons in the substantia nigra pars compacta, retrorubral area, and ventral tegmental area, except for a few THpositive neurons persisting in the medial part of the ventral tegmental area in some brains (Fig. $1 B$ ). Accordingly, very few TH-immunoreactive fibers were present in the ipsilateral host caudoputamen, nucleus accumbens, and olfactory tubercle, and very few were found in the grafts (see Figs. $1 A, 6 D$ ). Small numbers of TH-immunoreactive neurons were scattered in the denervated grafts, as they are in control grafts implanted into the host striatum without 6-OHDA lesions (Liu et al., 1990). These findings are in good accord with those reported by Labandeira-Garcia et al. (1991).

\section{Patterns of AChE staining and ChAT-like immunostaining}

Characteristic patchy regions of high $\mathrm{AChE}$ activity embedded in AChE-poor surrounds were present in all the control grafts (Fig. 2A), as previously documented (Sanberg et al., 1986; Isacson et al., 1987; Walker et al., 1987; Graybiel et al., 1989; Wictorin et al., 1989; Liu et al., 1990). A modular organization of AChE staining was also present in the denervated grafts (Figs. $2 B, 3 A, 4 A, 6 A$ ), but it was perceptibly different from that in the control grafts. The AChE staining intensity in the denervated grafts was generally weaker than that in the control grafts. In many of the denervated grafts $(n=7)$, the AChE-rich $P$ regions lacked borders as sharp as those in the control grafts (Figs. $3 A$, $4 A$ ). The size and shape of the $A C h E-$ rich $P$ regions varied from graft to graft in the 6-OHDA lesion group (Figs. $2 B, 3 A, 4 A$, $6 \mathrm{~A}$ ) as they did in the control group.

A few medium-sized and large ChAT-immunoreactive neurons were present in the control and the denervated grafts (Fig. $3 C, D)$. Clear ChAT immunostaining of the neuropil was obtained in one of the denervated brains. The ChAT-positive neuropil was mainly in patches, and some of these contained medium-sized to large ChAT-positive neurons. The ChAT-positive patches were spatially aligned with $A C h E-r i c h$ patches visible in adjacent sections (Fig. $3 A, B$ ). Thus, the ChAT-positive patches corresponded to $P$ regions. Scattered medium-sized bipolar ChAT-immunoreactive neurons were also present outside the
ChAT-positive $\mathrm{P}$ zones in the denervated grafts, as previously described for grafts in host striatum retaining normal dopaminergic innervation (Liu et al., 1990).

\section{Pattern of calbindin- $D_{28 K D}$-like immunostaining}

Two populations of calbindin- $\mathrm{D}_{28 \mathrm{~K} \mathrm{D}}$ (calbindin)-immunoreactive neurons with different phenotypes were present in the control grafts (Fig. 4C), as described in a previous report (Graybiel et al., 1989). Medium-sized calbindin-positive neurons resembling those in the host striatum were clustered in $\mathrm{P}$ regions. Outside these calbindin-positive patches, there were many medium-sized to large multipolar calbindin-immunoreactive neurons that did not resemble calbindin-positive neurons in the host striatum. The removal of TH-containing afferents did not appear to change this heterogeneity in the patterning of calbindin-like immunoreactivity in the grafts. Clusters of mediumsized neurons immunoreactive for calbindin were present in AChE-rich $P$ regions, and large calbindin-positive neurons with prominent dendrites were present in NP regions (Fig. $4 A, B, D$ ).

Pattern of dopamine- and adenosine

$3^{\prime}: 5$ '-monophosphate-regulated phosphoprotein

(DARPP-32)-like immunostaining

DARPP-32-like immunoreactivity in the control grafts (Fig. $5 \mathrm{~A}$ ) was distributed in patches as previously described (Wictorin et al., 1989) and in accord with the findings by Labandeira-Garcia et al. (1991), the destruction of TH-containing nigrostriatal afferents prior to grafting did not perceptibly alter this pattern. Distinct clusters of medium-sized neurons immunoreactive for DARPP-32 were present in the denervated grafts (Fig. $5 B$ ), and these DARPP-32-positive neurons (Fig. $5 D$ ) were similar to those in the control grafts (Fig. 5C) and in the host striatum. Close spatial alignments of DARPP-32-positive patches and AChE-rich $P$ regions in adjacent sections were also observed in both the denervated grafts (Fig. 6A,C) and the control grafts (data not shown). A few medium-sized DARPP-32-immunoreactive neurons were scattered outside DARPP-32-positive $P$ zones.

\section{Pattern of met-enkephalin-like immunostaining}

There were striking differences in the expression of met-enkephalin in the dopamine-innervated and dopamine-depleted grafts. In the control grafts, medium-sized met-enkephalin-immunoreactive neurons (Fig. $7 C$ ) with phenotypes similar to those in the normal striatum were clustered in patches as noted previously (Graybiel et al., 1989), and these met-enkephalin-positive patches were closely aligned with AChE-rich and DARPP$32-$ positive $P$ regions visible in adjoining sections. The intensity of immunostaining of the met-enkephalin-positive $P$ zones varied from patch to patch, but was generally similar to or slightly higher than that of the met-enkephalin-positive neurons and neuropil in the contralateral caudoputamen (Fig. 7A,C,D). Metenkephalin-immunoreactive neurons were distributed throughout the normal striatum, and in addition, a few patches containing densely immunostained neuropil appeared, mainly in the ventral and medial caudoputamen (Fig. 7A). Quantitative analysis indicated that the intensity of met-enkephalin-like immunostaining in the caudoputamen contralateral to the side of grafting did not differ between the control and 6-OHDA-treated rats except in the patches in the ventromedial caudoputamen.

The denervation of the host striatum resulted in marked changes in met-enkephalin-like immunostaining both in the grafts and in the surviving host caudoputamen ipsilateral to the 

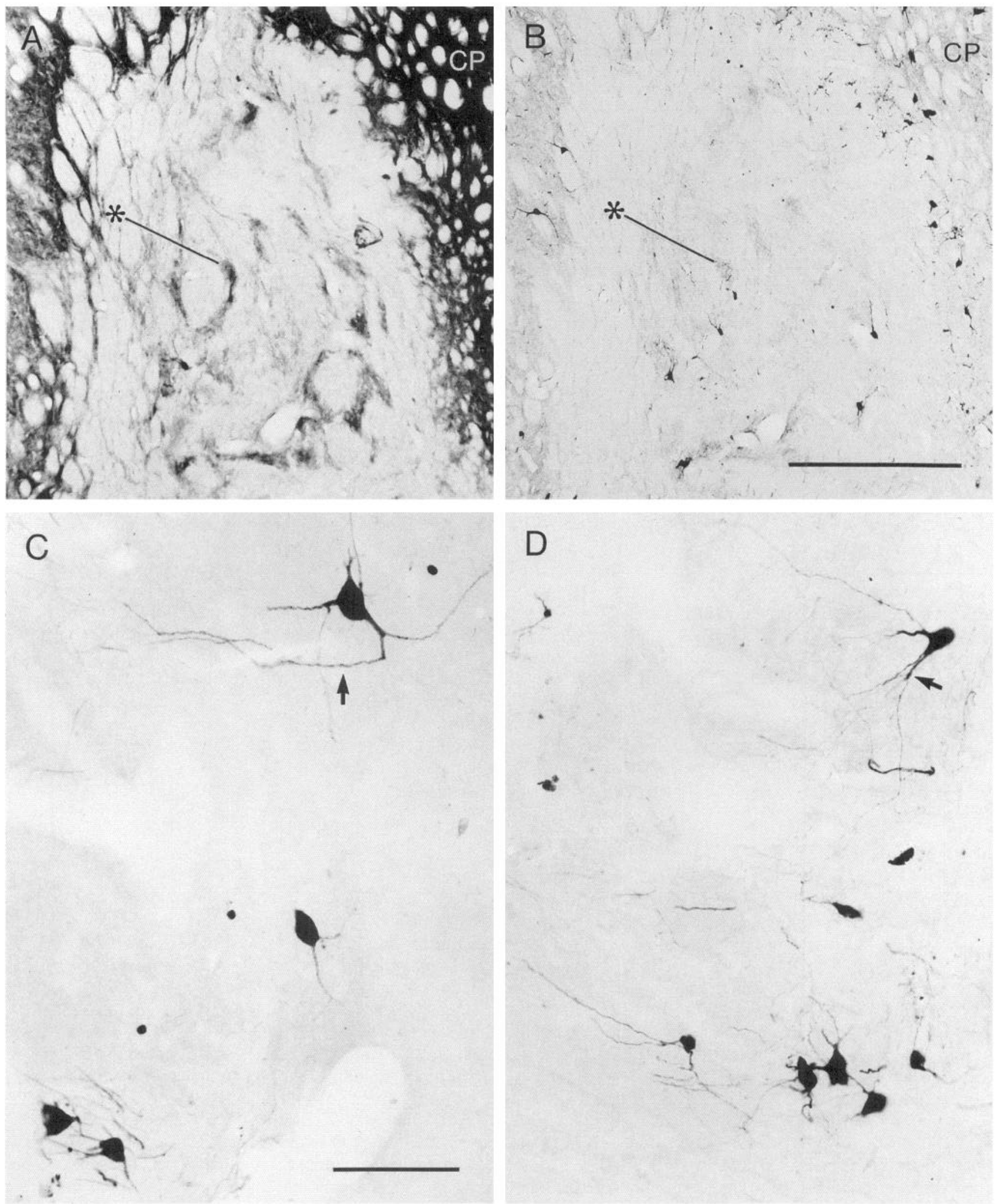

Figure 3. $A$ and $B$, Photomicrographs of adjacent sections stained for $\mathrm{AChE}(A)$ and for ChAT-like immunoreactivity $(B)$ illustrating the denervated striatal graft of case AG-78. Small AChE-rich P regions, most lacking sharp boundaries, are present in this denervated graft. Similarly, small weakly stained ChAT-positive patches are present in the graft as well as ChAT-immunoreactive neurons, a few of which lie in or beside the patches. The AChE-rich and ChAT-rich patches are coincident (example shown by asterisks). $C$ and $D$, High-magnification photomicrographs illustrating ChATimmunoreactive neurons in the control striatal graft of case AG-89 $(C)$ and the denervated striatal graft of case V-20 (D). A few medium-sized and large ChAT-positive neurons with elongated aspiny dendrites (examples at arrows) are present in the P regions of both the control and the denervated grafts. Staining of the neuropil is too weak to identify P zones (but see $B$ and Liu et al., 1990), but AChE-rich P zones were identified in serially adjacent sections. Some of the ChAT-immunoreactive neurons form clusters within the P regions. $C P$, caudoputamen. Scale bars: $B$ (for $A$ and $B$ ), $500 \mu \mathrm{m} ; C$ (for $C$ and $D$ ), $100 \mu \mathrm{m}$. 


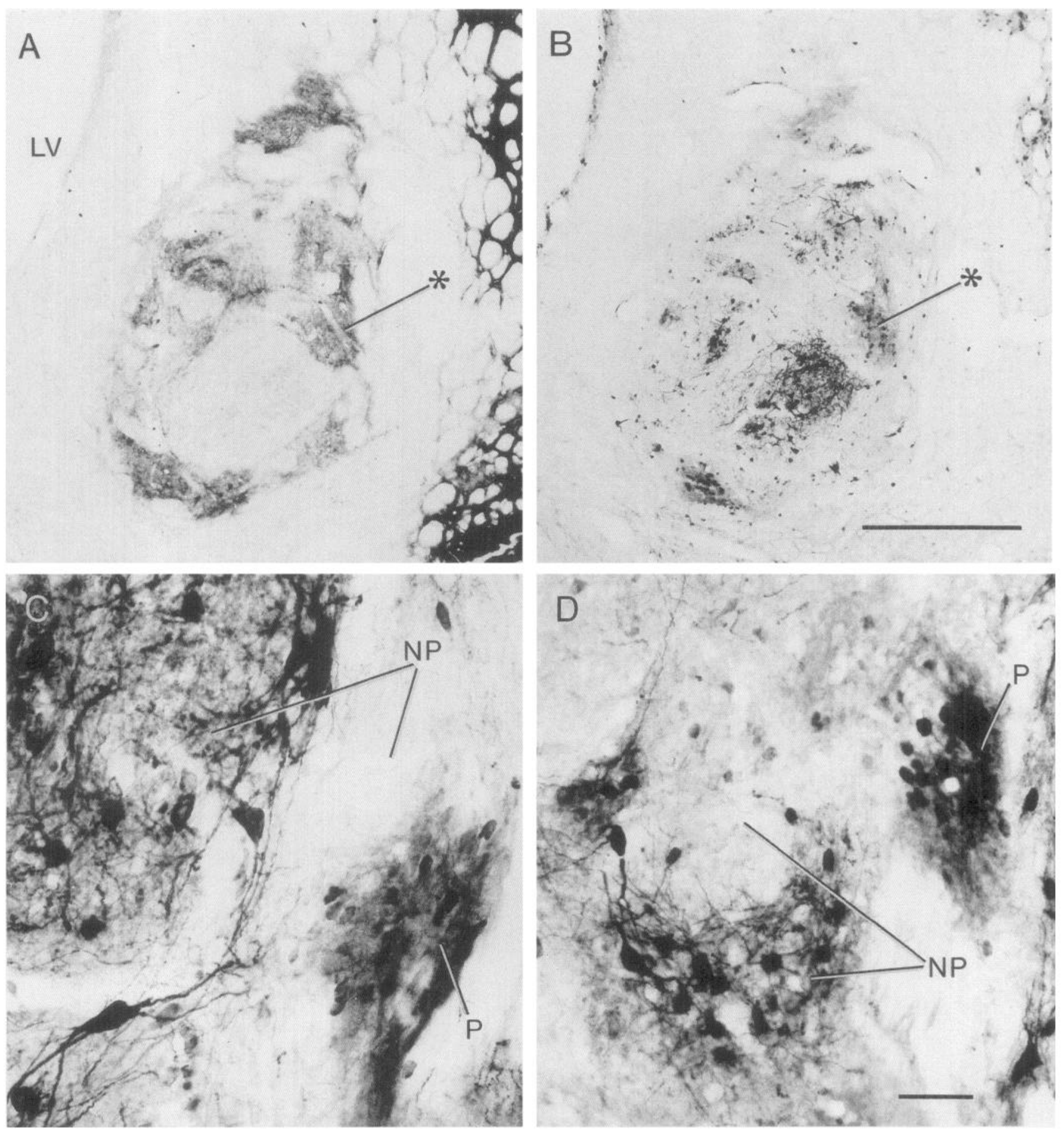

Figure 4. $A$ and $B$, Photomicrographs of adjoining sections stained for AChE $(A)$ and for calbindin-like immunoreactivity $(B)$ in the denervated striatal graft of case V-20. $C$ and $D$, High-magnification photomicrographs showing calbindin-positive neurons in the control striatal graft of case AG-89 $(C)$ and the denervated striatal graft of case AG-78 $(D)$. Calbindin-like immunoreactivity is distributed heterogeneously in the control graft and the denervated graft. In both grafts, patches of medium-sized calbindin-immunoreactive neurons $(P)$ are surrounded by NP zones $(N P)$ in which larger multipolar calbindin-positive neurons appear in clusters and singly. The patches of medium-sized calbindin-positive neurons are aligned with AChE-rich P regions in adjacent sections of the denervated graft (example shown by asterisks). $L V$, lateral ventricle. Scale bars: $B$ (for $A$ and $B$ ), $500 \mu \mathrm{m} ; D$ (for $C$ and $D$ ), $50 \mu \mathrm{m}$.

6-OHDA lesions. Within the denervated grafts, met-enkephalin-positive patches aligned with AChE-rich $\mathrm{P}$ regions were present (Fig. $6 A, B$ ), and the immunostaining intensity of many of these met-enkephalin-positive $P$ regions was greatly increased relative to the intensity seen in control grafts (Fig. $7 C, E$ ).
Quantitative analysis demonstrated that the increase in staining intensity of the $\mathrm{P}$ regions was significant ( $p<0.01$; Fig. 8). The increase resulted mainly from enhanced immunostaining of the neuropil in the patches; we did not detect obvious increases in numbers of immunostained cells. No substantial increase of 

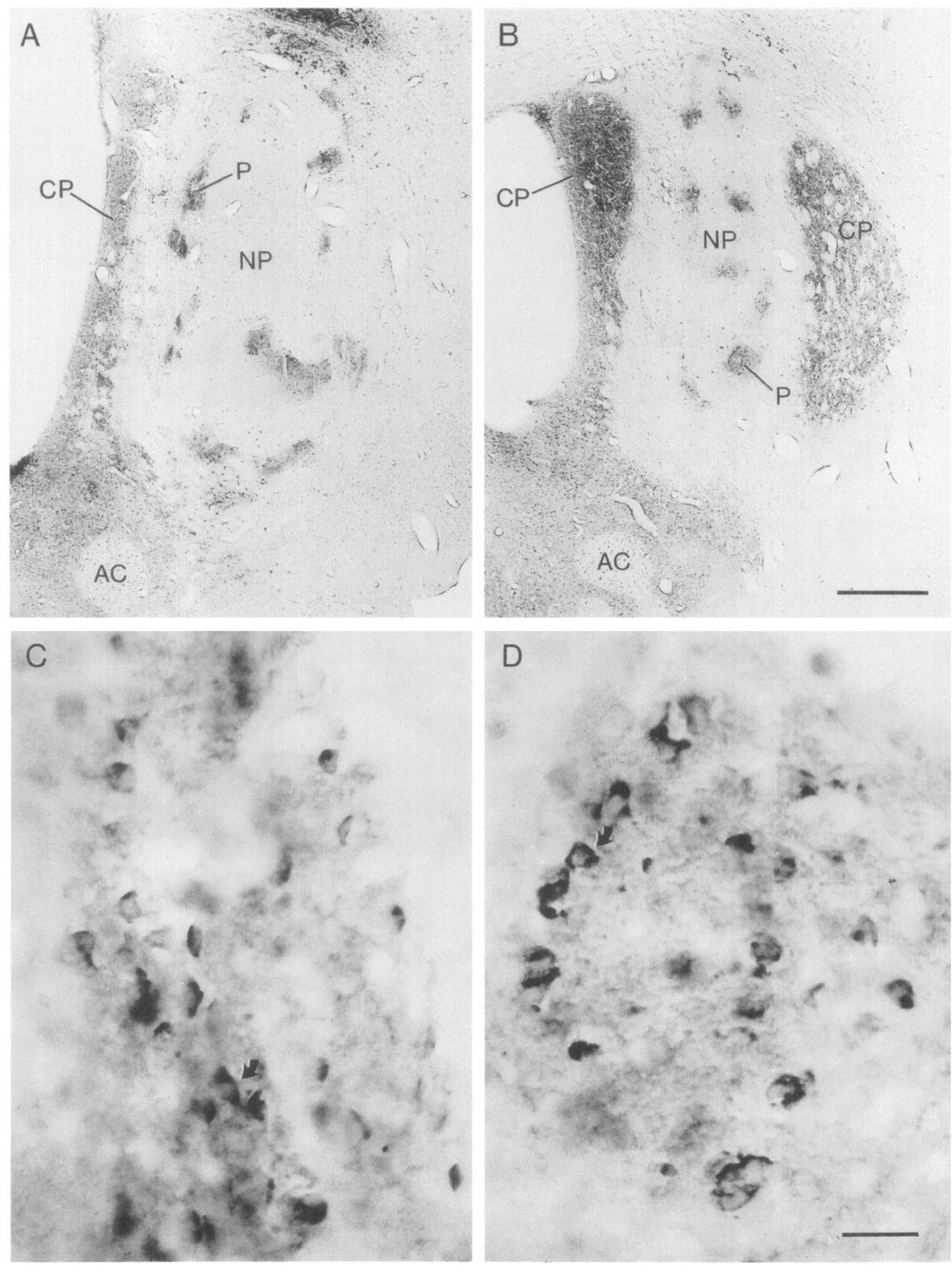
met-enkephalin-like immunostaining was observed in the NP regions of denervated grafts, despite the presence of some smallto medium-sized weakly stained met-enkephalin-immunoreactive cclls in NP regions. On the contrary, the met-enkephalinlike immunostaining of the NP regions was decreased in the denervated grafts relative to values for control graft NP regions $(p<0.01$; Fig. 8).

In the host caudoputamen, there was a much-enhanced heterogeneity in the distribution of met-enkephalin-like immunostaining (Fig. $7 B, F$ ). In addition, there was an obvious increase in the intensity of immunostaining. The increases in the medial and lateral host caudoputamen ipsilateral to 6-OHDA lesions relative to values in control host brains were statistically significant ( $p<0.01$; Fig. 8 ). The immunostaining of the metenkephalin-positive patches in the medial and ventral host caudoputamen ipsilateral to 6-OHDA lesions was also significantly increased (Fig. 8). Our measurements for the host striatum showed that there was also up-regulation of the ventral metenkephalin-positive patches on the side contralateral to the 6-OHDA injcctions ( $p<0.05$; data not shown). These results are in good accord with the findings of Voorn et al. (1987).

\section{Discussion}

The experiments reported here demonstrate a remarkable capacity of cells from embryonic striatal primordia to develop and to maintain striatal phenotypy in the absence of a TH-positive mesostriatal innervation. Our experiments further show that the grafted cells can form and maintain cell-type specific aggregates (the $P$ and NP regions) without this innervation. Our findings indicate, however, that mesostriatal fibers from the host brain are necessary to maintain normal levels of expression of metenkephalin-like peptide in such grafts. These contrasting findings suggest a dissociation between the developmental-inductive interactions and the chronic regulatory interactions of mesostriatal fibers with cells of embryonic striatal primordia grafted into the striatum.

\section{TH-positive fibers of $P$ zones in striatal grafts originate from host mesostriatal system}

The selective removal of TH-containing afferents innervating the host striatum a month or more prior to introducing embryonic cell suspension grafts resulted in elimination of nearly all the TH-positive patches in the embryonic striatal grafts. This observation establishes that the $\mathrm{TH}$-positive fibers innervating the $P$ regions of striatal grafts are derived from the midbrain catecholaminergic cell groups of the host, almost certainly the dopamine-containing mesostriatal cells. This conclusion is in accord with evidence from retrograde tract-tracing studies that striatal grafts can receive innervation by nigrostriatal afferents from the host (Pritzel et al., 1986; Wictorin et al., 1988). A few TH-positive neurons were scattered in the denervated grafts as in grafts into hosts without 6-OHDA lesions. The potential sources of these rare TH-positive neurons, as discussed previ- ously (Liu et al., 1990), may be from embryonic cortical or striatal cells. Our results suggest that these TH-positive neurons, although supporting local TH-positive processes, do not contribute in a major way to the TH-positive fiber plexus of $\mathrm{P}$ zones.

\section{Mesostriatal fibers from the host striatum are not required for induction or maintenance of the modular organization of striatal grafts}

It has been shown that TH-positive fibers appear in striatal grafts before the first appearance of clusters of DARPP-32-positive neurons representing $P$ regions (Labandeira-Garcia et al., 1991). These initial TH-positive fibers are not distributed in a patchy pattern. This sequence suggests that the initial ingrowing $\mathrm{TH}$ containing fibers from the host striatum might attract a subpopulation of grafted cells and stimulate them to form $P$ regions in the grafts. Labandeira-Garcia et al. (1991) did report, however, a subsequent sprouting of fine $\mathrm{TH}$-positive fibers from the initial coarse TH-positive fibers within DARPP-32-positive patches. This observation raised the possibility that the THpositive fibers responded to cues from $P$ zone cells.

Our findings provide direct evidence that after the complete or nearly complete removal of TH-positive host fibers in the grafts, the modular organization of the grafts, as characterized by the occurrence of $\mathrm{P}$ zones containing ChAT-positive neurons, medium-sized DARPP-32-positive, met-enkephalin-positive, and calbindin-positive neurons, as well as AChE-positive and ChAT-positive neuropil, still can be achieved. These results strongly suggest that the ingrowing TH-positive fibers from the host striatum are not required either for the process of inducing a subpopulation of grafted cells to form P regions in the grafts, or for the processes of maintaining these striatum-like cellular aggregates.

Target selectivity has been documented for dopamine-containing nigrostriatal fibers in vitro and in vivo. They preferentially innervate striatal tissue over other types of tissue when given choices in both tissue culture and intracranial graft conditions (Hemmendinger et al., 1981; Björklund et al., 1983; DenisDonini et al., 1983; Won et al., 1989; Ostergaard et al., 1991). We and others have argued elsewhere that the modular organization of embryonic striatal grafts reflects an admixture of striatal tissue (AChE-rich P regions) and nonstriatal tissue (AChEpoor NP regions) rather than an immature state of striosome/ matrix compartmentation in which the AChE-rich $\mathrm{P}$ zones are protostriosomes (Graybiel et al., 1989; Wictorin et al., 1989; Liu et al., 1990, 1991b). The implication of our findings is that the selective innervation of the $P$ regions by host TH-positive fibers probably represents a further example of the target-selecting capability of mesostriatal afferents: the TH-containing afferents are attracted to $\mathrm{P}$ zone cells, rather than the reverse.

Our experiments leave open the possibility that the E15 embryonic striatal primordia we used as donor tissue could have been influenced by the earliest (E14)-arriving mesostriatal fibers

Figure 5. Photomicrographs showing the patterns of immunostaining for DARPP-32 in the control graft of case AG-89 $(A)$ and in the denervated graft of case V-18 $(B)$. Similar clusters of DARPP-32-immunoreactive neurons $(P)$ appear in both the control and the denervated striatal grafts. Neurons in the $\mathrm{P}$ regions indicated by $P$ in $A$ and $B$ are illustrated at higher magnification in $C$ and $D$, respectively. The neurons in the $P$ regions of the control and the denervated grafts are medium sized, and they have similar phenotypes (examples at curved arrows). The regions outside the $\mathrm{P}$ zones (NP zones, $N P$ ) in both the control and the denervated grafts contain only a few scattered medium-sized DARPP-32-positive neurons. $C P$, caudoputamen; $A C$, anterior commissure. Scale bars: $B$ (for $A$ and $B$ ), $500 \mu \mathrm{m} ; D$ (for $C$ and $D$ ), $25 \mu \mathrm{m}$. 


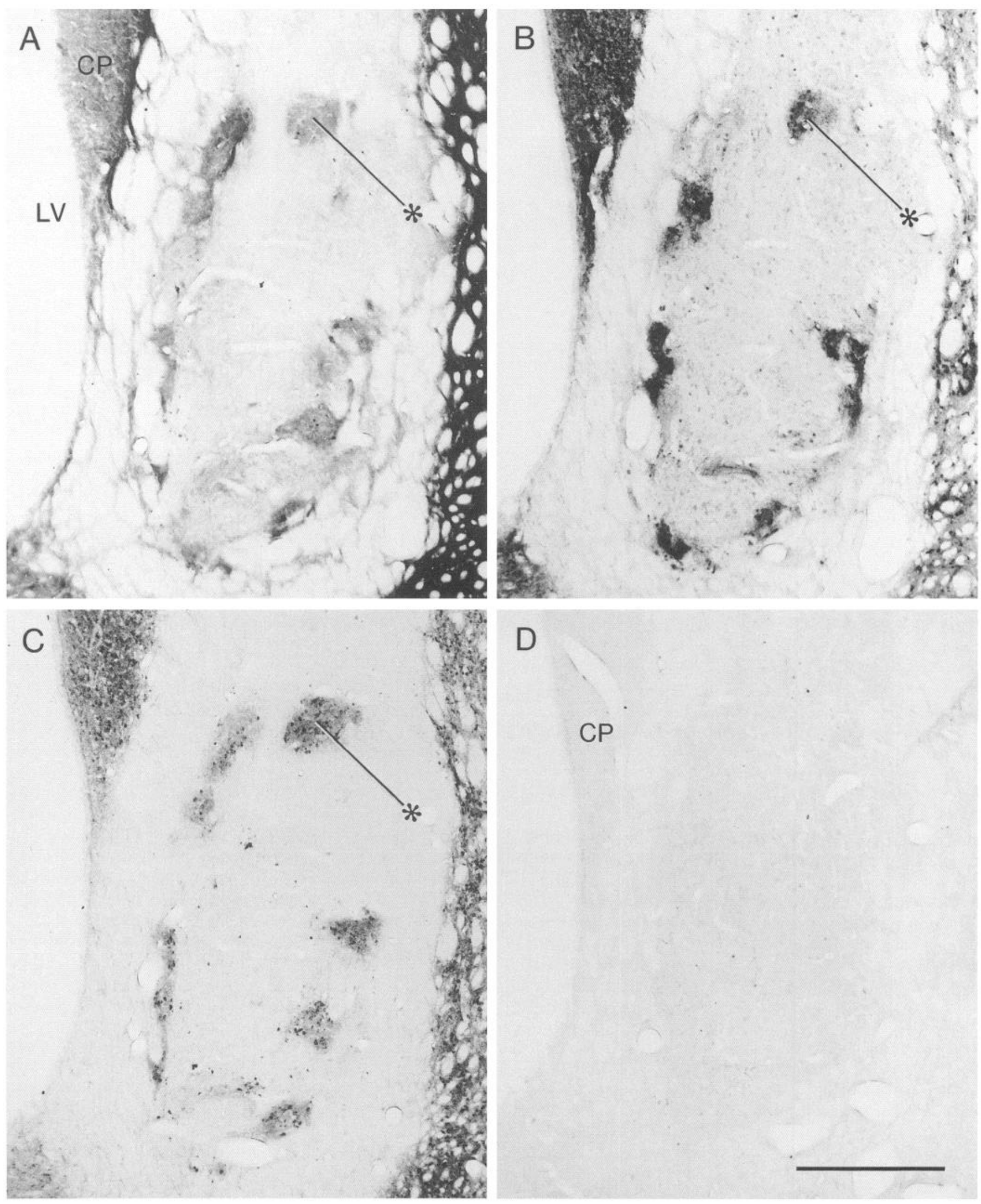

Figure 6. Photomicrographs of adjoining sections stained for AChE $(A)$, met-enkephalin-like immunoreactivity $(B)$, DARPP-32-like immunoreactivity $(C)$, and TH-like immunoreactivity $(D)$ in the denervated striatal graft of case V-18. Patches of met-enkephalin-positive neurons and DARPP-32-positive neurons are aligned with AChE-rich $\mathrm{P}$ regions (examples at asterisks). Very little TH-like immunoreactivity is present. $L V$, lateral ventricle; $C P$, caudoputamen. Scale bar, $500 \mu \mathrm{m}$. 
developing in the donor brains prior to transplantation. This possibility does not alter our conclusion that, once the donor cells are dissociated and transplanted into the ibotenate-damaged host striatum, mesostriatal afferents are unnecessary for aggregation of the cells and for the modular pattern formation characteristic of the developed grafts. The observation that $\mathrm{P}$ region aggregates can form without exposure to host $\mathrm{TH}$-positive fibers suggests that cellular mechanisms other than those dependent on dopamine-containing afferents, such as preferential adhesion among striatal cells and repulsion between striatal and nonstriatal cells, may underlie the formation of $P$ and NP zones in the grafts.

\section{Expression of cholinergic markers in embryonic striatal grafts implanted into host striatum denervated by 6-OHDA lesions before grafting}

It is well established that functional interactions exist between the dopaminergic and cholinergic systems of the mature striatum. Electron microscopic studies have shown close appositions between the TH-containing terminals and ChAT-immunoreactive dendrites and perikarya (Kubota et al., 1987; Chang, 1988; Pickel and Chan, 1990). Furthermore, in situ hybridization studies have documented expression of dopamine D2 receptor mRNA by most of the large neurons of the striatum, which are known to be the cholinergic interneurons (Brené et al., 1990; Le Moine et al., 1990a,b; Weiner et al., 1991). Our finding that large ChAT-positive neurons were present in the denervated grafts suggests that removal of incoming TH-containing afferents before transplantation does not profoundly change the differentiation process of cholinergic neurons in embryonic striatal grafts. For technical reasons, we had only limited material in which ChAT-positive neuropil in the grafts could be analyzed. In the available sections, we observed patches of ChAT-positive neuropil, and these also were apparently similar to ChAT-positive patches found in control grafts, though in general smaller. We cannot discount the possibility that $\mathrm{TH}$-immunoreactive fibers associated with the sparsely scattered $\mathrm{TH}$-positive neurons in the grafts were sufficient to induce the expression of ChAT-like immunoreactivity in cells and neuropil of the denervated grafts, but these rare TH-positive neurons were not particularly associated with the $P$ zones. It is not known whether ChAT-positive neurons can develop in the dopamine-depleted developing striatum in utero, but Brené et al. (1990) have reported that the removal of nigrostriatal afferents of the young adult striatum by 6-OHDA lesions does not alter lcvels of striatal ChAT mRNA.

Despite this apparent independence of cholinergic neuronal differentiation in the denervated striatal grafts, the pattern of AChE staining in the grafts was not altogether normal. It has been reported that about $12 \%$ of striatal AChE activity is present in dopaminergic nigrostriatal axons and terminals (Lehmann and Fibiger, 1978). Therefore, the lack of crispness in the AChE staining pattern in the denervated grafts might have resulted from removal of $\mathrm{AChE}$ activity associated with nigrostriatal afferents. AChE in the striatum is associated mainly with cholinergic neurons but is also expressed by some noncholinergic neurons (Bolam et al., 1984). Therefore, second-order (including transynaptic) anterograde effects following the 6-OHDA lesions could also underlie the changes of $A C h E$ expression we found. During normal development, destruction of dopamine-containing inputs to the developing striatum in the perinatal period does not profoundly alter the AChE staining pattern in the post- natal striatum (Snyder-Keller, 1991). Subtle changes do occur, however, as there is more pronounced heterogeneity in the $\mathrm{AChE}$ staining in the developing striatum than in the striatum of rats without lesions (Liu, Dunnett, and Graybiel, unpublished observations).

The cholinergic neurons of the striaturn are among the earliest cells born during striatal neurogenesis (Semba et al., 1988; Phelps et al., 1989). The majority of them are generated at E12-E15. However, in contrast to the early expression of DARPP-32 by medium-sized striatal neurons (Foster et al., 1987), ChAT-like immunoreactivity in large striatal neurons is not detectable in the developing rat striatum until E18 (see Fig. 1 in Armstrong ct al., 1987), by which time many $\mathrm{TH}$-and dopamine-containing fibers are already present in the striatal anlage (Specht et al., 1981; Moon Edley and Herkenham, 1984; Voorn et al., 1988). This developmental time lag between neurogenesis and ChAT expression by cholinergic neurons suggests that the induction of ChAT-like immunoreactivity may be triggered by signals other than those from early-arriving nigrostriatal afferents. On the other hand, ChAT activity is increased in striatal tissue cocultured with ventral mesencephalon (Kessler, 1986).

Expression of DARPP-32-like immunoreactivity in embryonic striatal grafts implanted into host striatum denervated by 6-OHDA lesions before grafting

One of the most clear-cut findings in the present study is that the expression of DARPP-32 by the grafted neurons in the $P$ regions was not perceptibly affected by prior catecholaminergic denervation of the host striatum. Distinct clusters of D $\mathrm{R} P P$ 32-immunoreactive neurons still appeared in the denervated grafts, and these DARPP-32-positive neurons were similar to the neurons in the DARPP-32-positive $P$ zone cell clusters found in grafts with intact dopamine-containing afferents. It has also been shown that denervation of TH-containing afferents of striatal grafts several months after grafting does not change the immunostaining pattern of DARPP-32 in the grafts (Wictorin et al., 1989). Together, these findings suggest that the expression of DARPP-32, a phosphoprotein thought to be associated with dopamine D1-like receptor subtypes (Walaas and Greengard, 1984; Sunahara et al., 1991), is probably not regulated in embryonic striatal grafts by TH-containing afferents from the host.

This situation for striatal grafts is compatible with in vivo and in vitro evidence on regulation of DARPP-32 expression in the developing and mature striatum. The immunoreactivity and biochemical activity of DARPP- 32 in the adult rat striatum are not altered by the removal of dopaminergic input in the neonatal period or at adulthood (Luthman et al., 1990; Raisman-Vozari et al., 1990). Furthermore, chronic injections of the dopamine D1 receptor antagonist $\mathrm{SCH} 23390$ into adult rats does not change the level of DARPP-32 mRNA (Grebb et al., 1990). DARPP32 levels in the dopamine-deficient striatum of patients with Parkinson's disease are not different from those in controls (Raisman-Vozari et al., 1990). Finally, coculturing striatal cells with mesencephalic cells does not change DARPP-32 levels in the striatal neurons (Ehrlich et al., 1990).

All these different lines of evidence suggest that the development of DARPP-32 expression and its later regulation in the striatum are largely independent of the dopaminergic nigrostriatal innervation. Dopamine-containing nigrostriatal afferents may, however, play a role in the induction of striatal DARPP-32 expression during development. The onset of DARPP-32 expression in striatal grafts has been reported to be delayed about 

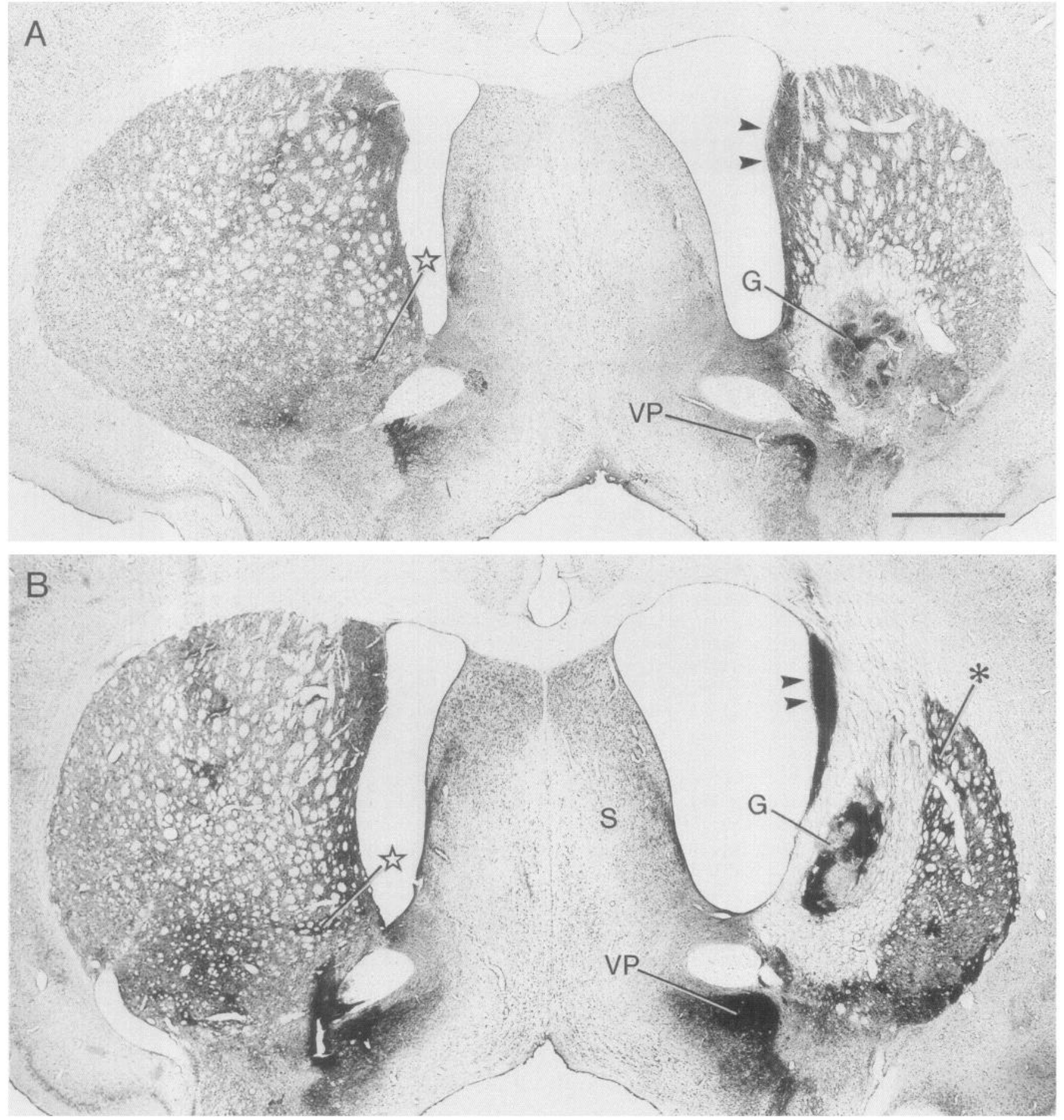

Figure 7. Photomicrographs illustrating met-enkephalin-like immunostaining patterns in the control striatal graft $(G)$ of case AG-94 $(A)$ and the denervated striatal graft of case $\mathrm{V}-18(B)$. High-magnification photographs of the control and the denervated grafts are shown in $C$ and $E$, respectively. The host caudoputamen adjacent to the control and to the denervated grafts is shown at high magnification in $D$ and $F$, respectively. The arrows in $C-F$ indicate fiducial marks for alignment of $C$ with $D$ and $E$ with $F$. Patches of met-enkephalin-like immunoreactivity $(P)$ with weakly immunostained surrounds $(N P)$ are present in both the control and the denervated grafts. The met-enkephalin-like immunostaining in the $\mathrm{P}$ regions of the denervated graft $(B, E)$ is more intense than that in the $\mathrm{P}$ regions of the control graft $(A, C)$; for quantitative measurements, see Figure 8 . An upregulation of the met-enkephalin-like immunostaining is also evident in the denervated host caudoputamen, especially in the region (double arrowheads in $B$ ) adjacent to the lateral ventricle, in a rim (double asterisks in $F$ ) along the ventrolateral caudoputamen and in patches distributed through the remaining caudoputamen (examples at single asterisks in $B, F$ ). No such striking increase in met-enkephalin-like immunoreactivity is present in the host caudoputamen ipsilateral to the control graft $(A, D)$, nor is there unusually intense immunostaining in the caudoputamen contralateral to the control graft $(A)$. In the caudoputamen contralateral to the denervated graft $(B)$, met-enkephalin-like immunostaining is also normal except ventrally, in the ventromedial met-enkephalin-rich patches (examples at stars). Quantitative measurements show upregulation in these patches $(p<0.05$; data not shown). Note that the met-enkephalin-like immunostaining in the ventral pallidum $(V P)$ ipsilateral to the 6-OHDA lesion also appears greatly increased. $S$, septum; $f b$, fiber bundles. Scale bars: $A$ (for $A$ and $B$ ), $1 \mathrm{~mm} ; D$ (for $C-F$ ), $500 \mu \mathrm{m}$. 


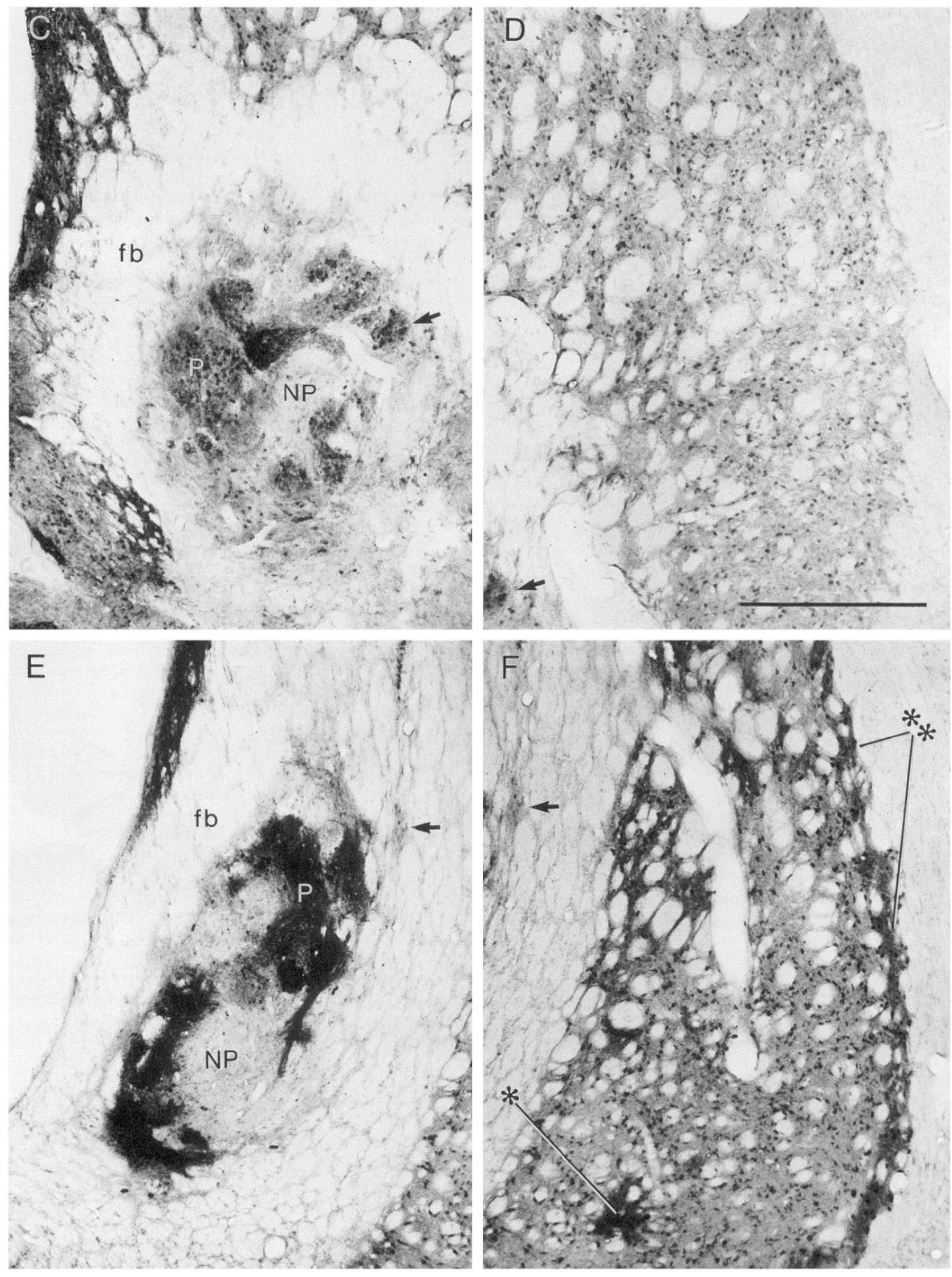




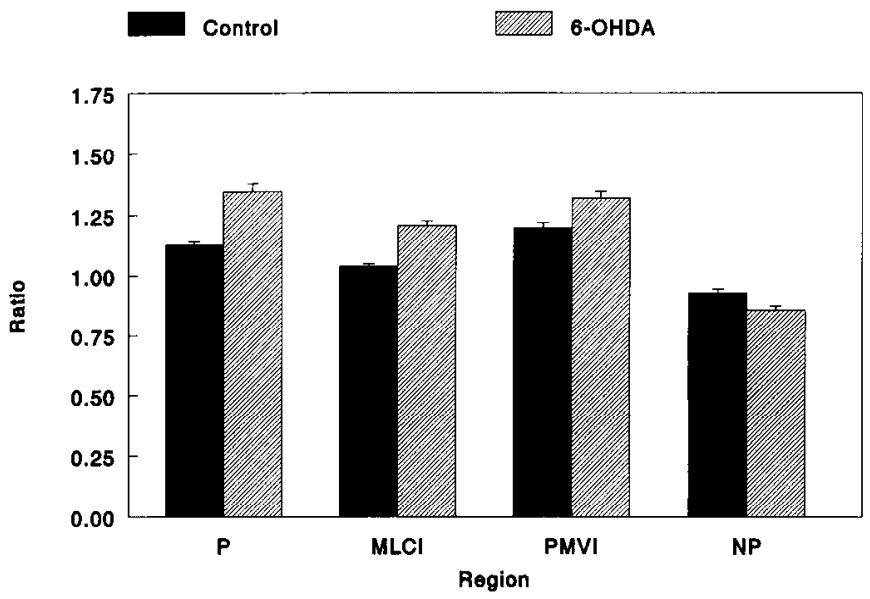

Figure 8. Histogram illustrating the results of quantitative analysis of met-enkephalin-like immunostaining in the control (solid bars) and the denervated (hatched bars) striatal grafts. Mean gray scale values (see Materials and Methods) were measured for the $\mathrm{P}$ regions $(P)$ and NP regions $(N P)$ of both the denervated and control grafts and, in the ipsilateral host caudoputamen of the two sets of brains, for the medial and lateral caudoputamen $(M L C I)$ and the ventromedial patches of heightened met-enkephalin-like immunostaining $(P M V I)$. As the immunostaining intensity in the caudoputamen contralateral to the graft side was not altered in the 6-OHDA-treated rats except in the patches in the medial and ventral caudoputamen ( $p<0.05$; data not shown), the immunostaining intensity of the measured regions ipsilateral to the graft side was expressed relative to the averaged immunostaining intensity of the regions outside the ventromedial patches in the contralateral caudoputamen. The ratio values illustrated in the bar graph represent the means of these ratios pooled from different sections. Data represent mean ratios \pm SEM. All of these normalized values for matched regions from the brains with 6-OHDA lesions and without 6-OHDA lesions were statistically significant $(p<0.01)$. Individual $p$ values were, for $P, p=6 \times 10^{-7}$; for $M L C I, p=2.87 \times 10^{-7}$; for $P M V I, p=0.001$; and for $N P, p=0.004$; demonstrated by two-tailed $t$ tests. The metenkephalin-like immunostaining in the host caudoputamen ( $M L C I$ and $P M V I$ ipsilateral to the grafts was higher in the grafted brains with 6-OHDA lesions than in those without 6-OHDA lesions, and the intensity of met-enkephalin-like immunoreactivity in the $P$ regions of the denervated grafts was increased relative to $P$ regions in the control grafts. By contrast, the immunostaining density in the NP regions of the denervated grafts was lower than that in the NP regions of the control grafts.

$8 \mathrm{~d}$ in grafts placed in the host striatum previously treated with 6-OHDA lesions (Onteniente et al., 1990). Moreover, a few THand dopamine-containing nigrostriatal fibers reach the rat striatal primordium as early as E14 (Specht et al., 1981; Moon Edley and Herkenham, 1984; Voorn et al., 1988), a day before we took donor tissue. Thus, we cannot rule out the possibility that such early-arriving TH- and dopamine-containing fibers in the donor striatal primordia had preconditioning effects on the subsequent expression of DARPP-32 in the grafts. As mentioned above for the ChAT-positive system of the grafts, THimmunoreactive fibers from the scattered TH-positive neurons in the denervated grafts also could be capable of triggering the expression of DARPP-32 in the grafts. These arguments apply equally to the calbindin system, discussed below.

\section{Expression of calbindin-like immunoreactivity in embryonic striatal grafts implanted into host striatum denervated by 6-OHDA lesions before grafting}

Calbindin is expressed in the medium-sized neurons of the striatal matrix at adulthood (Gerfen et al., 1985) and throughout development (Liu and Graybiel, 1992). We have previously shown that striatal grafts contain two different populations of calbindin-positive neurons (Graybiel et al., 1989). The mediumsized calbindin-positive neurons clustered in $\mathrm{P}$ zones resemble mature calbindin-positive striatal neurons. Calbindin-positive neurons in NP regions have a nonstriatal phenotype. Our results clearly demonstrate that the destruction of TH-containing afferents before grafting does not prevent the expression of calbindin-like immunoreactivity by either population of neurons. Denervation of the striatum by perinatal 6-OHDA lesions also does not change the subsequent pattern of calbindin expression in the striatum (Snyder-Keller, 1991).

\section{Regulation of met-enkephalin-like immunoreactivity in striatal grafts}

Striking effects of dopamine-containing nigrostriatal afferents on the expression of striatal neuropeptide have been shown in the mature striatum (for review, see Graybiel, 1990). For the cnkephalincrgic systcm of the striatum, depletion of dopaminergic signaling either by 6-OHDA lesions or by pharmacological blockade with dopamine D2 receptor-selective antagonists results in significant increases of enkephalin levels and of preproenkephalin and proenkephalin mRNAs (Hong et al., 1978; Young et al., 1986; Normand et al., 1987, 1988; Romano et al., 1987; Sivam et al., 1987; Voorn et al., 1987; Morris et al., 1988; Gerfen et al., 1991). It therefore has been suggested that dopamine-containing nigrostriatal afferents normally exert a tonic inhibitory effect on the enkephalinergic system of the mature striatum. This regulatory influence seems to apply to the enkephalinergic system in the postnatal striatum of rats with 6-OHDA lesions made during the neonatal period (Sivam et al., 1987; Chen and Weiss, 1991).

Our findings demonstrate that denervation of the host striatum before introducing embryonic striatal grafts also results in enhanced met-enkephalin-like immunostaining in the $\mathrm{P}$ zones of the grafts. We therefore suggest that the met-enkephalinpositive neurons in the $P$ regions of striatal grafts are sensitive to the control of TH-containing afferents from the host striatum, and that in the absence of these inputs, they respond by increasing met-enkephalin expression as do neurons of the host. Consistent with this suggestion is evidence that dopamine D2like (and D1-like) receptor binding sites and cells expressing proenkephalin mRNA and enkephalin are predominately present in the $P$ regions of striatal grafts (Isacson et al., 1987; Graybiel et al., 1989; Liu et al., 1990; see also Deckel et al., 1988; Mayer et al., 1990; Sirinathsinghji et al., 1990; Helm et al., 1991; Lu et al., 1991). Signaling mechanisms similar to those in the normal striatum could thus underlie the upregulation of met-enkephalin-like immunoreactivity we report here. Similar regulation also has been observed following dopamine receptor blockade by $\mathrm{A}$. Björklund and coworkers (personal communication).

An argument against this conclusion could be made by suggesting that the darkly stained met-enkephalin-positive $P$ regions of the denervated grafts represent tissue of the ventral caudoputamen, in which there normally are patches of strong metenkephalin-like immunoreactivity even in the normal rat. This is unlikely, however, because our quantitative analysis shows that the met-enkaphlin-like immunoreactivity in the $P$ regions of the control grafts was significantly less than that in the $P$ regions of the denervated grafts (Fig. 8), despite the fact that $P$ regions representing ventral caudoputamen should be present in the control as well as the denervated grafts. Moreover, much 
of the increased staining in the met-enkephalin-positive patches in the normal ventromedial caudoputamen is in the neuropil and is probably derived from afferent fibers rather than from intrinsic striatal neurons. We did note that not all met-enkephalin-positive neurons in the host striatum seem to be subjected to equal regulation by dopaminergic inputs, because the increases in met-enkephalin-like immunostaining we found on the side of the 6-OHDA lesions were in patchy regions heterogeneously distributed through the caudoputamen. We found little heterogeneity in the $P$ regions of the denervated grafts. The enhanced immunostaining of the $P$ zones may have obscured nonresponsive met-enkephalin-positive neurons in the $P$ regions. Alternatively, in the novel graft environment, met-cnkephalinpositive striatal neurons that normally would not respond to denervation by 6-OHDA lesions may become sensitive to dopaminergic regulation.

The specific regulation by $\mathrm{TH}$-containing afferents of the $\mathbf{P}$ zone is consistent with our previous suggestion that the striatum-like $\mathrm{P}$ regions are the principal zones in which functional integration between the graft and host occurs by way of reconstructed striatal circuits (Liu et al., 1990, 1991b). We have no way to account for the apparent downregulation of met-enkephalin in the NP regions. These regions of the grafts receive only sparse innervation by TH-positive fibers in control grafts (Graybiel et al., 1987; Isacson et al., 1987; Clarke et al., 1988; Liu et al., 1990). Most of the met-enkephalin-immunoreactive neurons present in the NP regions do not have the morphology of normal striatal cells (Graybiel et al., 1989). Such cells may respond by downregulating enkephalin on being deprived of the sparse catecholaminergic input to the NP regions. Alternatively, they may respond indirectly to the catecholaminergic denervation of the host.

The $P$ regions are the principal sites within the grafts giving rise to outputs to the host pallidum (Wictorin et al., 1989). Enkephalin is a principle coexisting neuropeptide in the GABAergic striatopallidal pathway (Cuello and Paxinos, 1978; Haber and Elde, 1981; Aronin et al., 1984). This pathway, in turn, controls the subthalamic nucleus, which is thought to modulate activity in the pallidothalamic "release circuit" of the basal ganglia (Albin et al., 1989; DeLong, 1990; Graybiel, 1990). Reconstituting normal enkephalinergic regulation in striatal grafts could thus help to ensure normal release function of pallidal outflow pathways in the host brain.

\section{References}

Albin RL, Young AB, Penney JB (1989) The functional anatomy of basal ganglia disorders. Trends Neurosci 12:366-375.

Armstrong DM, Bruce G, Hersh LB, Gage FH (1987) Development of cholinergic neurons in the septal/diagonal band complex of the rat. Dev Brain Res 36:249-256.

Aronin N, DiFiglia M, Graveland GA, Schwartz WJ, Wu J-Y (1984) Localization of immunoreactive enkephalins in GABA synthesizing neurons of the rat neostriatum. Brain Res 300:376-380.

Bayer SA (1984) Neurogenesis in rat striatum. Int J Dev Neurosci 2: 163-175.

Besson M-J, Caboche J, Rogard M, Zalc B, Mallet J, Vernier P, Julien J-F (1991) Tonic inhibitory role of D2 receptors in the regulation of GAD mRNA expression. Soc Neurosci Abstr 17:852.

Björklund A, Stenevi U, Schmidt RH, Dunnett SB (1983) Intracerebral grafting of neuronal cell suspensions. II. Survival and growth of nigral cells implanted in different brain sites. Acta Physiol Scand [Suppl] 522:11-22.

Bolam JP, Ingham CA, Smith AD (1984) The section-Golgi-impregnation procedure. 3 . Combination of Golgi-impregnation with enzyme histochemistry and electron microscopy to characterize acetyl- cholinesterase-containing neurons in the rat neostriatum. Neuroscience 12:687-709.

Brené S, Lindefors N, Herrera-Marschitz M, Persson H (1990) Expression of dopamine $\mathrm{D} 2$ receptor and choline acetyltransferase mRNA in the dopamine deafferented rat caudate-putamen. Exp Brain Res 83:96-104.

Chang HT (1988) Dopamine-acetylcholine interaction in the rat striatum: a dual labeling immunocytochemistry. Brain Res Bull 21:295304

Chen JF, Weiss B (1991) Ontogenetic expression of $\mathrm{D}_{2}$ dopamine receptor mRNA in rat corpus striatum. Dev Brain Res 63:95-104.

Clarke DJ, Dunnett SB, Isacson O, Sirinathsinghji DJS, Björklund A (1988) Striatal grafts in rats with unilateral ncostriatal lesions. I. Ultrastructural evidence of afferent synaptic inputs from the host nigrostriatal pathway. Neuroscience 24:791-801.

Cuello AC, Paxinos G (1978) Evidence for a long leu-enkephalin striopallidal pathway in rat brain. Nature 271:178-180.

Deckel AW, Moran TH, Robinson RG (1988) Receptor characteristics and recovery of function following kainic acid lesions and fetal transplants of the striatum. II. Dopaminergic systems. Brain Res 474:3947.

DeLong MR (1990) Primate models of movement disorders of basal ganglia origin. Trends Neurosci 13:281-289.

Denis-Donini S, Glowinski J, Prochaintz A (1983) Specific influence of striatal target neurons on the in vitro outgrowth of mesencephalic dopaminergic neurites: a morphological quantitative study. J Neurosci 3:2292-2299.

Ehrlich ME, Rosen NL, Kurihara T, Shalaby IA, Greengard P (1990) DARPP-32 development in the caudate nucleus is independent of afferent input from the substantia nigra. Dev Brain Res 54:257-263.

Fentress JC, Stanfield BB, Cowan WM (1981) Observations on the development of the striatum in mice and rats. Anat Embryol 163: 275-298.

Foster GA, Schultzberg M, Hökfelt T, Goldstein M, Hemmings HC Jr, Ouimet CC, Walaas SI, Greengard P (1987) Development of a dopamine- and cyclic adenosine $3^{\prime}: 5^{\prime}$-monophosphate regulated phosphoprotein (DARPP-32) in the prenatal rat central nervous system, and its relationship to the arrival of presumptive dopaminergic innervation. J Neurosci 7:1994-2018.

Gale K, Segovia J, Tillakaratne NJK, Whelan K, Tobin AJ (1988) Dopaminergic control of striatal GABA synthesis is reflected in the expression of mRNA for striatal glutamic acid decarboxylase. Soc Neurosci Abstr 14:1066.

Geneser-Jensen FA, Blackstad JW (1971) Distribution of acetylcholinesterase in the hippocampal region of the guina pig. Z Zellforsch Mikrosk Anat 114:460-481.

Gerfen CR, Baimbridge KG, Miller JJ (1985) The neostriatal mosaic: compartmental distribution of calcium-binding protein and parvalbumin in the basal ganglia of the rat and monkey. Proc Natl Acad Sci USA 82:8780-8784.

Gerfen CR, McGinty JF, Young WS III (1991) Dopamine differentially regulates dynorphin, substance $\mathrm{P}$, and enkephalin expression in striatal neurons: in situ hybridization histochemical analysis. J Neurosci 11:1016-1031.

Graybiel AM (1984) Correspondence between the dopamine islands and striosomes of the mammalian striatum. Neuroscience 13:11571187.

Graybiel AM (1990) Neurotransmitters and neuromodulators in the basal ganglia. Trends Neurosci 13:244-254.

Graybiel AM, Chesselet M-F (1984) Distribution of cell bodies expressing substance $\mathrm{P}$, enkephalin, and dynorphin $\mathrm{B}$ in kitten and cat striatum. Anat Rec 208:64A.

Graybiel AM, Hickey TL (1982) Chemospecificity of ontogenetic units in the striatum: demonstration by combining $\left[{ }^{3} \mathrm{H}\right]$ thymidine neuronography and histochemical staining. Proc Natl Acad Sci USA 79: 198-202.

Graybiel AM, Ragsdale CW (1978) Histochemically distinct compartments in the striatum of human, monkey, and cat demonstrated by acetylthiocholinesterase staining. Proc Natl Acad Sci USA 75: 5723-5726.

Graybiel AM, Dunnett SB, Baughman RW, Liu F-C (1987) Cholinergic neurons and neuropil and tyrosine hydroxylase-positive fibers cluster together in circumscribed patches in intrastriatal grafts derived from embryonic striatal donor tissue. Neuroscience [Suppl] 22:S265. Graybiel AM, Liu F-C, Dunnett SB (1989) Intrastriatal grafts derived 
from fetal striatal primordia. I. Phenotypy and modular organization. J Neurosci 9:3250-3271.

Grebb JA, Girault JA, Ehrlich M, Greengard P (1990) Chronic treatment of rats with SCH-23390 or raclopride does not affect the concentrations of DARPP-32 or its mRN $\Lambda$ in dopamine-innervated brain regions. J Neurochem 55:204-207.

Guennoun R, Bloch B (1991) $D_{2}$ dopamine receptor gene expression in the rat striatum during ontogeny: an in situ hybridization study. Dev Brain Res 60:79-87.

Haber SN, Elde RP (1981) Correlation between met-enkephalin and substance $\mathrm{P}$ immunoreactivity in the primate globus pallidus. Neuroscience 9:245-260.

Helm GA, Robertson MW, Jallo GI, Simmons N, Bennett JP (1991) Development of D1 and D2 dopamine receptors and associated second messenger systems in fetal striatal transplants. Exp Neurol 111: $181-189$

Hemmendinger LM, Garber B, Hoffmann PC, Heller A (1981) Target neuron-specific process formation by embryonic mesencephalic dopamine ncurons in vitro. Proc Natl Acad Sci USA 78:1264-1268.

Hong JS, Yang H-YT, Fratta W, Costa E (1978) Rat striatal methionine-enkephalin content after chronic treatment with cataleptogenic and noncataleptogenic antischizophrenic drugs. J Pharmacol Exp Ther 205:141-147.

Hong JS, Yoshikawa K, Kanamatsu T, Sabol SL (1985) Modulation of striatal enkephalinergic neurons by antipsychotic drugs. Fed Proc 44:2535-2539.

Isacson O, Dawbarn D, Brundin P, Gage FH, Emson PC, Björklund A (1987) Neural grafting in a rat model of Huntington's disease: striosomal-like organization of striatal grafts as revealed by immunohistochemistry and receptor autoradiography. Neuroscience 22:481-497.

Jiang H-K, McGinty JF, Hong JS (1990) Differential modulation of striatonigral dynorphin and enkephalin by dopamine receptor subtypes. Brain Res 507:57-64.

Kessler JA (1986) Differential regulation of cholinergic and peptidergic development in the rat striatum in culture. Dev Biol 113:77-89.

Krushel LA, Connolly JA, van der Kooy D (1989) Pattern formation in the mammalian forebrain: patch neurons from the rat striatum selectively reassociate in vitro. Dev Brain Res 47:137-142.

Kubota Y, Inagaki S, Shimada S, Kito S, Eckenstein F, Tohyama M (1987) Neostriatal cholinergic neurons receive direct synaptic inputs from dopaminergic axons. Brain Res 413:179-184.

Labandeira-Garcia JL, Wictorin K, Cunningham ET Jr, Björklund A (1991) Development of intrastriatal grafts and their afferent innervation from the host. Neuroscience 42:407-426.

Laijiness ME, Chio CL, Hyslop DK, Huff RM (1991) Stimulation of mitogenesis in transfected CHO cells by activation of the D2 receptor. Soc Neurosci Abstr 17:818.

Lander AD (1989) Understanding the molecules of neural cell contacts: emerging patterns of structure and function. Trends Neurosci 12:189-195.

Lankford KL, DeMello FG, Klein WL (1988) $\mathrm{D}_{1}$-type dopamine receptors inhibit growth cone motility in cultured retina neurons: evidence that neurotransmitters act as morphogenic growth regulators in the developing central nervous system. Proc Natl Acad Sci USA 85:2839-2843.

Lehmann J, Fibiger HC (1978) Acetylcholinesterase in the substantia nigra and caudate-putamen of the rat: properties and localization in dopaminergic neurons. J Neurochem 30:61 5-624.

Le Moine C, Normand E, Guitteny AF, Fouque B, Teoule R, Bloch B (1990a) Dopamine gene receptor expression by enkephalin neurons in rat forebrain. Proc Natl Acad Sci USA 87:230-234.

Le Moine C, Tison F, Bloch B (1990b) D2 dopaminergic receptor gene expression by cholinergic neurons in the rat striatum. Neurosci Lett 117:248-252.

Li SJ, Sivam SP, McGinty JF, Huang YS, Hong J-S (1987) Dopaminergic regulation of tachykinin metabolism in the striatonigral pathway. J Pharmacol Exp Ther 243:792-798.

Liu F-C, Graybiel AM (1992) Heterogeneous development of calbindin- $D_{28 \mathrm{~K}}$ expression in the striatal matrix. J Comp Neurol 320:304 322.

Liu F-C, Graybiel AM, Dunnett SB, Baughman RW (1990) Intrastriatal grafts derived from fetal striatal primordia. II. Reconstitution of cholinergic and dopaminergic systems. J Comp Neurol 295:1-14.

Liu F-C, Dunnett SB, Graybiel AM (1991a) The influence of TH- containing afferents on the development of modular organization in embryonic striatal grafts. Soc Neurosci Abstr 17:853.

Liu F-C, Dunnett SB, Robertson HA, Graybiel AM (1991b) Intrastriatal grafts derived from fetal striatal primordia. III. Induction of modular patterns of Fos-like immunoreactivity by cocaine. Exp Brain Res 85:501-506.

Lu S, Shipley MT, Norman AB, Sanberg PR (1991) Striatal, ventral mesencephalic and cortical transplants into the intact striatum: a neuroanatomical study. Exp Neurol 113:109-130.

Luthman L, Lindqvist E, Young D, Cowburn R (1990) Neonatal dopamine lesion in the rat results in enhanced adenylate cyclase activity without altering dopamine receptor binding or dopamine- and adenosine $3^{\prime}: 5^{\prime}$-monophosphate-regulated phosphoprotein (DARPP-32) immunoreactivity. Exp Brain Res 83:85-95.

Marchand R, Lajoie L (1986) Histogenesis of the striopallidal system in the rat. Neurogenesis of its neurons. Neuroscience 17:573-590

Mayer E, Heavens RP, Sirinathsinghji DJS (1990) Autoradiographic localization of D1 and D2 dopamine receptors in primordial striatal tissue grafts in rats. Neurosci Lett 109:271-276.

McCobb DP, Haydon PG, Kater SB (1988) Dopamine and serotonin inhibition of neurite elongation of different identified neurons. J Neurosci Res 19:19-26.

Merchant KM, Bush L, Gibb JW, Hanson GR (1988) Receptor-specific interactions of the nigro-striatal dopamine projections with striatal neurotensin systems in rat brain. Soc Neurosci Abstr 14:114.

Moon Edley S, Herkenham M (1984) Comparative development of striatal opiate receptors and dopamine revealed by autoradiography and histofluorescence. Brain Res 305:27-42.

Morris BJ, Höllt V, Herz A (1988) Dopaminergic regulation of striatal proenkephalin mRNA and prodynorphin mRNA: contrasting effects of D1 and D2 antagonists. Neuroscience 25:525-532.

Müller F, O'Rahilly R (1988) The development of the human brain, including the longitudinal zoning in the diencephalon at stage 15 . Anat Embryol 179:55-71.

Müller F, O'Rahilly R (1990) The human brain at stages 21-23, with particular reference to the cerebral cortical plate and to the development of the cerebellum. Anat Embryol 182:375-400.

Newman-Gage H, Graybiel AM (1988) Expression of calcium/calmodulin-dependent protein kinase in relation to dopamine islands and synaptic maturation of cat striatum. J Neurosci 8:3360-3375.

Normand E, Popovici T, Fellmann D, Bloch B (1987) Anatomical study of enkephalin gene expression in the rat forebrain following haloperidol treatment. Neurosci Lett 83:232-236.

Normand E, Popovici T, Onteniente B, Fellmann D, Piatier-Tonneau D, Auffray C, Bloch B (1988) Dopaminergic neurons in the substantia nigra modulate preproenkephalin $\mathrm{A}$ gene expression in rat striatal neurons. Brain Res 439:39-46.

Onteniente B, Peschanski M, Desfontaines B (1990) Phenotypic differentiation of striatal transplanted neurons in relation to dopaminergic host afferents. Soc Neurosci Abstr 16:974.

Oppenheim RW (1991) Cell death during development of the nervous system. Annu Rev Neurosci 14:453-501.

Østergaard K, Schou JP, Gähwiler BH, Zimmer J (1991) Tyrosine hydroxylase immunoreactive neurons in organotypic slice cultures of the rat striatum and neocortex. Exp Brain Res 83:357-365.

Phelps PE, Brady DR, Vaughn JE (1989) The generation and differentiation of cholinergic neurons in rat caudate-putamen. Dev Brain Res 46:47-60.

Pickel VM, Chan J (1990) Spiny neurons lacking choline acetyltransferase immunoreactivity are major targets of cholinergic and catecholaminergic terminals in rat striatum. J Neurosci Res 25:263-280.

Pritzel M, Isacson O, Brundin P, Wiklund L, Björklund A (1986) Afferent and efferent connections of striatal grafts implanted into the ibotenic acid lesioned neostriatum in adult rats. Exp Brain Res 65: 112-126.

Purves D, Lichtman JW (1985) Principles of neural development. Sunderland, MA: Sinauer.

Raisman-Vozari R, Girault JA, Moussaoui S, Feuerstein C, Jenner P, Marsden CD, Agid Y (1990) Lack of change in striatal DARPP-32 levels following nigrostriatal dopaminergic lesions in animals and in Parkinsonian syndromes in man. Brain Res 507:45-50.

Romano GJ, Shivers BD, Harlan RE, Howells RD, Pfaff DW (1987) Haloperidol increases proenkephalin mRNA levels in the caudate- 
putamen of the rat: a quantitative study at the cellular level using in situ hybridization. Mol Brain Res 2:33-41.

Sales N, Martres MP, Bouthenet ML, Schwartz JC (1989) Ontogeny of dopaminergic $D_{2}$ receptors in the rat nervous system: characterization and detailed autoradiographic mapping with [' $\left.{ }^{125} I\right]$ iodosulpiride. Neuroscience 28:673-700.

Sanberg PR, Henault MA, Deckel AW (1986) Locomotor hyperactivity: effects of multiple striatal transplants in an animal model of Huntington's disease. Pharmacol Biochem Behav 25:297-300.

Schambra UB, Duncan GE, Breese GR, Fornaretto MG, Caron MG, Fremeau RT Jr (1991) Ontogeny of mRNA for dopamine receptor subtypes (D1, D2, D3) in the rat brain. Soc Neurosci Abstr 17:539.

Semba K, Vincent SR, Fibiger HC (1988) Different times of origin of choline acetyltransferase- and somatostatin-immunoreactive neurons in the rat striatum. J Neurosci 8:3937-3944.

Sidman RL, Rakic P (1982) Development of the human central nervous system. In: Histology and histopathology of the nervous system (Haymaker W, Adams RD, eds), pp 3-145. Springfield, IL: Thomas.

Sirinathsinghji DJS, Morris BJ, Wisden W, Northrop A, Hunt SP, Dunnett SB (1990) Gene expression in striatal grafts. I. Cellular localization of neurotransmitter mRNAs. Neuroscience 34:675-686.

Sivam SP, Breese GR, Krause JE, Napier TC, Mueller RA, Hong J-S (1987) Neonatal and adult 6-hydroxydopamine-induced lesions differentially alter tachykinin and enkephalin gene expression. J Neurochem 49:1623-1633.

Smart IHM, Sturrock RR (1979) Ontogeny of the neostriatum. In: The neostriatum (Divac I, Oberg R, Guanila E, eds), pp 127-146. New York: Pergamon.

Snyder-Keller AM (1991) Development of striatal compartmentalization following pre- and postnatal dopamine depletion. J Neurosci 11: $810-821$.

Soghomonian J-J, Gonzales C, Chesselet M-F (1991) Nigrostriatal lesions differentially affect mRNAs encoding glutamate-decarboxylase (GADs) in subpopulations of striatal neurons. Soc Neurosci Abstr $17: 856$.

Specht LA, Pickel VM, Joh TH, Reis DJ (1981) Light microscopic immunocytochemical localization of tyrosine hydroxylase in prenatal rat brain. I. Early ontogeny. J Comp Neurol 199:233-254.

Sternberger LA (1979) Immunocytochemistry. New York: Wiley.

Sunahara RK, Guan H-C, O'Dowd BF, Seeman P, Laurier LG, Ng G, George SR, Torchia J, Van Tol HHM, Niznik HB (1991) Cloning of the gene for a human dopamine $\mathrm{D}_{5}$ receptor with higher affinity for dopamine than $D_{1}$. Nature 350:614-619.

Vernier P, Julien J-F, Rataboul P, Fourrier O, Feuerstein C, Mallet J
(1988) Similar time course changes in striatal levels of glutamic acid decarboxylase and proenkephalin mRNA following dopaminergic deafferentation in the rat. $\mathrm{J}$ Neurochem 51:1375-1380.

Voorn P, Roest G, Groenewegen HJ (1987) Increase of enkephalin and decrcase of substance $P$ immunoreactivity in the dorsal and ventral striatum of the rat after midbrain 6-hydroxydopamine lesions. Brain Res 412:391-396.

Voorn P, Kalsbeek A, Jorritsma-Byham B, Groenewegen HJ (1988) The pre- and postnatal development of the dopaminergic cell groups in the ventral mesencephalon and the dopaminergic innervation of the striatum of the rat. Neuroscience 25:857-888.

Walaas SI, Greengard P (1984) DARPP-32, a dopamine- and adenosine $3^{\prime}: 5^{\prime}$-monophosphate-regulated phosphoprotein enriched in dopamine-innervated brain regions. I. Regional and cellular distribution in the rat brain. $\mathrm{J}$ Neurosci 4:84-98.

Walaas SI, Sedvall G, Greengard P (1989) Dopamine-regulated phosphorylation of synaptic vesicle-associated proteins in rat neostriatum and substantia nigra. Neuroscience 29:9-19.

Walker PD, Chovanes GI, McAllister JP II (1987) Identification of acetylcholinesterase-reactive neurons and neuropil in neostriatal transplants. J Comp Neurol 259:1-12.

Weiner DM, Levey AI, Sunahara RK, Niznik HB, O'Dowd BF, Seeman $P$, Brann MR (1991) D1 and D2 dopamine receptor mRNA in rat brain. Proc Natl Acad Sci USA 88:1859-1863.

Weiss LT, Chesselet M-F (1989) Regional distribution of prepro-somatostatin messenger RNA in the striatum, as revealed by in situ hybridization histochemistry. Mol Brain Res 5:121-130.

Wictorin K, Isacson O, Fischer W, Nothias F, Peschanski M, Björklund A (1988) Connectivity of striatal grafts implanted into the ibotenic acid-lesioned striatum. I. Subcortical afferents. Neuroscience 27:547562.

Wictorin K, Ouimet CC, Björklund A (1989) Intrinsic organization and connectivity of intrastriatal striatal transplants in rats as revealed by DARPP-32 immunohistochemistry: specificity of connections with the lesioned host brain. Eur J Neurosci 1:690-701.

Won L, Heller A, Hoffmann PC (1989) Selective association of dopamine axons with their striatal target cells in vitro. Dev Brain Res 47:93-100.

Young WS III, Bonner TI, Brann MR (1986) Mesencephalic dopamine neurons regulate the expression of neuropeptide mRNAs in the rat forebrain. Proc Natl Acad Sci USA 83:9827-9831.

Zhou FC, Buchwald N (1989) Connectivities of the striatal grafts in adult rat brain: a rich afference and scant striatonigral efference. Brain Res 504:15-30. 